\title{
Characterization of agar from Gracilaria tikvahiae cultivated for nutrient bioextraction in open water farms
}

\author{
Cristina M.R. Rocha ${ }^{\mathrm{a}, \mathrm{b}, *}$, Ana M.M. Sousa ${ }^{\mathrm{a}}$, Jang K. Kim, ${ }^{\mathrm{c}, \mathrm{e}}$, Júlia M.C.S. Magalhães ${ }^{\mathrm{a}}$, \\ Charles Yarish $^{\mathrm{c}}$, Maria do Pilar Gonçalves ${ }^{\mathrm{a}}$ \\ ${ }^{a}$ REQUIMTE, LAQV, Departamento de Engenharia Química, Faculdade de Engenharia, Universidade do Porto, Rua Dr. Roberto Frias, 4200-465, Porto, Portugal \\ ${ }^{\mathrm{b}}$ CEB - Centre of Biological Engineering, University of Minho, Campus de Gualtar, 4710-057, Braga, Portugal \\ ${ }^{\mathrm{c}}$ Departments of Ecology \& Evolutionary Biology and Marine Sciences, University of Connecticut-Stamford, 1 University Place, Stamford, CT, 06901, USA \\ ${ }^{\mathrm{d}}$ Department of Marine Science, School of Natural Sciences, Incheon National University, 119 Academy-ro, Yeonsu-gu, Incheon, 22012, South Korea \\ ${ }^{\mathrm{e}}$ Research Institute of Basic Sciences, Incheon National University, 119, Academy-ro, Yeonsu-gu, Incheon, 22012, South Korea
}

\section{A R T I C L E I N F O}

\section{Keywords:}

Agar

Extraction

Yield

Gel strength

Nutrient bioextraction

Gracilaria tikvahiae

\begin{abstract}
A B S T R A C T
Gracilaria tikvahiae, an endemic western North Atlantic red alga, was cultivated for nutrient bioextraction in urbanized estuarine waters in Long Island Sound and the Bronx River Estuary, USA. This study assesses the feasibility of an integrated approach of using G. tikvahiae produced in this bioextraction system as sustainable biomass source for agar production. Agars were extracted after alkaline pre-treatment and characterized in terms of gelling strength, chemical composition, chemical structure and gel structure. Results indicated that this seaweed performed similar to other cultivated Gracilaria in terms of extraction yield and gelling strength of the agar. Differences between sites were not significant in terms of agar gel strength, though yield was higher at Long Island Sound. The extracted agars were sulfated, methylated and with no detectable pyruvate substituents. It is possible to use an integrated strategy of nutrient bioextraction in urbanized estuarine waters and agar exploitation with G. tikvahiae.
\end{abstract}

\section{Introduction}

With increasing ecological concerns and with the world aiming to build a sustainable future, the use of biodegradable and biocompatible materials is becoming a true necessity of modern times. In this respect, seaweed polysaccharides have long been explored in the manufacture of biomaterials covering a broad spectrum of areas as diverse as food, biomedical, pharmaceutical and biotechnological sciences (Matsuhashi, 1990; Pereira \& Yarish, 2008; Rinaudo, 2008). Agars extracted from some red seaweeds are made up of two main fractions: agarose and agaropectin. Agarose is a neutral polysaccharide responsible for the gelling ability of agar and its basic repeating unit is the alternating 1,3linked $\beta$-D-galactopyranose and 1,4-linked 3,6-anhydro- $\alpha$-L-galactopyranose. Agaropectin results from the presence of several substituent groups in the basic repeating unit such as sulfates, methyl ethers and pyruvates at different positions along the polysaccharide chain and constitutes the non-gelling polymer fraction (Lahaye \& Rochas, 1991; Rees, 1969). Depending on the molecular weight and on the type, pattern and degree of substitution, different functional properties are achieved and a wide range of applications can be considered
(Villanueva, Sousa, Goncalves, Nilsson, \& Hilliou, 2010).

The ability to produce commercial grade seaweed polysaccharides in sufficient amounts that enable a broader exploitation of these biomaterials is a crucial step towards its sustainability. Commercial grade agars are mainly extracted from red seaweeds, including species of Gelidium and/or Gracilaria/Gracilariopsis. Bacteriological or pharmaceutical agars and agarose are traditionally produced from wild harvested Gelidium. Gracilaria/Gracilariopsis species usually lead to weaker agar gels, suitable for food applications, but these taxa are easily cultivated. Gracilaria/Gracilariopsis have been mostly cultivated in two Asian countries, China and Indonesia. These two countries produce approximately $98 \%$ of global production (FAO, 2016; Kim, Yarish, Hwang, Park, \& Kim, 2017). In the Americas, Chile produces nearly 13 tons of dried extract powder per year with an annual value of US \$29 million (FAO, 2016). Agars from Gelidium present typically a low degree of substitution and, thus low sulfate content, resulting in agars with high gel strength. On the other hand, agars from Gracilaria/Gracilariopsis have usually higher sulfate contents resulting in lower gelling capability. However, geographic factors, seasonal variations, growth stages, nutrient availability and environmental conditions can influence

\footnotetext{
* Corresponding author. CEB - Centre of Biological Engineering, University of Minho, Campus de Gualtar, 4710-057, Braga, Portugal.

E-mail address: cmrochainv@gmail.com (C.M.R. Rocha).
} 
the synthesis, yield and chemistry of agar leading to a high heterogeneity of agars (Lahaye \& Rochas, 1991). The extraction conditions (e.g. time, temperature, solvent to seaweed ratio) can also be refined to produce agars with an enhanced gelling ability (Arvizu-Higuera, Rodriguez-Montesinos, Murillo-Alvarez, Munoz-Ochoa, \& HernandezCarmona, 2008; Sousa, Alves, Morais, Delerue-Matos, \& Goncalves, 2010). Chemical treatments are also used for improving the properties of extracted agars. Alkaline hydrolysis of agars from Gracilaria prior to extraction allows the conversion of L-galactose 6-sulfate units to the 3,6anhydro-L-galactose residues responsible for the ability of the polymer to form a gel.

Agar's unique gelling properties make it particularly suitable for food applications. Its gelling strength is high, even at low concentrations, gelation is reversible, though it only melts above $80^{\circ} \mathrm{C}$ avoiding the need for refrigeration (an advantage over gelatin), and it can retain its gelling ability even at high temperature, allowing proper sterilization. Furthermore, its high temperatures resistance widens its usability, allowing, e.g., its use as thickening or stabilizing agent in the baking industry. In adition, it is tasteless and does not need the presence of extra reagents to induce gelation, being preferred over a wide range of other phycocolloids or gums. In fact, ca. $90 \%$ of the produced agar is used for food applications (McHugh, 2003), and its price is generally higher than for other food grade phycocolloids (Porse \& Rudolph, 2017). Nevertheless, other emerging food applications include its use in low fat food as a fat replacer, in prebiotics, and as an edible filmforming or coating-forming agent.

No short term shortage of Gracilaria is predicted, due to the growth of Chinese and Indonesian production and processing capacities, and its price has decreased significantly in this last decade (Porse \& Rudolph, 2017). However, this decrease in the price of raw materials did not have relevant impact in the final price of food grade agar. Due to the alarming decrease in natural populations of Gelidium, high grade agar is becoming scarce (Porse \& Rudolph, 2017; Santos \& Melo, 2018).

Seaweeds can be used as biofilters, removing nutrients, heavy metals and other organic and inorganic matters from the ecosystem. This process is now called nutrient bioextraction (Kim, Kraemer, \& Yarish, 2014, 2015a; Rose et al., 2015). Some species of Gracilaria have proven to be good candidates for nutrient bioextraction removing inorganic nutrients from urbanized coastal waters (Abreu et al., 2009; Abreu, Pereira, Yarish, Buschmann, \& Sousa-Pinto, 2011; Kim et al., 2014; Rose et al., 2015). The high volume of biomass generated in these nutrient bioextraction systems can lead to a sustainable source of these hydrocolloids.

Gracilaria tikvahiae is native to western Atlantic Ocean, extending from Nova Scotian, cold temperate regions, to Florida and into the Caribbean, warm subtropical regions (Ganesan, 1989; Littler \& Littler, 2000; Mathieson \& Hehre, 1986; McLachlan, 1979; Schneider, Suyemoto, \& Yarish, 1979). This alga is known to be a highly opportunistic species occurring in eutrophic estuaries and bays (Peckol \& Rivers, 1995). G. tikvahiae may grow up to $40 \mathrm{~cm}$ long and its thallus color can be highly variable, ranging from dark green to red and brown (Littler, Littler, Bucher, \& Norris, 1989). Green mutants have been reported (Kim, Mao, Kraemer, \& Yarish, 2015b). Its branches spread irregularly and can be either somewhat flattened or cylindrical (Littler et al., 1989). Interestingly, particular morphtypes can persist even when cultured under uniform conditions, suggesting the morphological differences are genetically controlled (Patwary \& Meer, 1984). Gracilaria tikvahiae is a euryhaline species (Bird, Chen, \& McLachlan, 1979; McLachlan \& Bird, 1984). For example, G. tikvahiae collected from Tampa Bay, FL survived salinities between 8 and $60 \mathrm{ps} \mu$ and was reported to grow well between 15 and $35 \mathrm{ps \mu}$ (Bird \& McLachlan, 1986). Furthermore, G. tikvahiae grows well at high temperature up to $29^{\circ} \mathrm{C}$ but was found to not grow at prolonged sub-optimal temperatures (e.g. $<15^{\circ} \mathrm{C}$; Lapointe, Rice, \& Lawrence, 1984; Gorman, Kraemer, Yarish, Boo, \& Kim, 2017).

There have been attempts to cultivate Gracilaria tikvahiae to use the biomass as a source of agar in North America (Bird, Hanisak, \& Ryther, 1981; Cheney, Mar, Saga, \& Meer, 1986; Craigie \& Jurgens, 1989; Craigie \& Wen, 1984). These authors have not only cultivated local populations of $G$. tikvahiae but also developed selected mutants. Some mutants (e.g. MP-40 and MP-44) showed superior characteristics in terms of their agar quality in comparison to the wild type clones (Patwary \& Vandermeer, 1983; 1984). Although the extraction of agar from Gracilaria tikvahiae was a very active pursuit at laboratory scale in the 1980s, we are not aware of any studies on agar extraction from this species during recent years. Furthermore, no studies were found dealing with the integrated exploitation of agars from bioextraction systems, nor with the agar extraction from G. tikvahiae cultivated in open waters.

This study follows a field-scale evaluation of Gracilaria tikvahiae aquaculture as a nutrient bioextraction strategy in Long Island Sound and the Bronx River Estuary, USA. Therefore, the objective of this study was to assess the feasibility of integrating the exploitation of agars in bioextraction systems using Gracilaria tikvahiae. Seaweeds were cultivated at two different open water farms, Long Island Sound (LIS) and at the mouth of the Bronx River estuary (BRE), and the agar quality from the cultivated Gracilaria biomass was monitored in terms of yield, gel strength (GS), sulfate and 3,6-anhydro-L-galactose content contents (3,6-AG), gel structure and NMR chemical and structural profile.

\section{Materials and methods}

Commercial agar (ref. A-7002 with an ash content of 2-4.5\%) was obtained from Sigma-Aldrich Co. (St. Louis, MO). All other chemicals were of analytical grade.

\subsection{Cultivation and sampling}

Gracilaria tikvahiae (G-RI-ST ${ }_{1}$ ) was cultivated by means of two, $50 \mathrm{~m}$ long-line culture systems at two, near-shore sites in Long Island Sound (LIS; Fairfield, CT; $41^{\circ} 06.882^{\prime} \mathrm{N} / 7^{\circ}{ }^{\circ} 15.277^{\prime} \mathrm{W}$ ) and at the mouth of the Bronx River Estuary (BRE; Bronx, NY; 40 $48.047^{\prime} \mathrm{N} / 73^{\circ} 52.164^{\prime} \mathrm{W}$ ). The long-lines were deployed at two depths $(0.5 \mathrm{~m}$ and $1.0 \mathrm{~m})$ in July 28 , 2011 in LIS and in September 20, 2011 at the BRE site. Twenty gram bundles of G. tikvahiae thalli were inserted into nylon rope (5/8" high liner sink line) for every condition tested. The samples were randomly collected from each seaweed culture unit and then transferred to the laboratory in a cooler within $2 \mathrm{~h}$. After the material was washed with autoclaved seawater, the samples were dried in an oven at $55^{\circ} \mathrm{C}$ until they were completely dried.

Salinity at the LIS site during the growing season ranged from 26 to $30 \mathrm{ps} \mu$. The salinity at the BRE site was slightly lower and ranged from 20 to $25 \mathrm{ps} \mu$. Light penetration did not differ between sites during the growing season. At the LIS site, the light penetration was $81.2 \%$ $(\mathrm{SD} \pm 9.2 \%)$ at $0.5 \mathrm{~m}$ and $53.2 \%(\mathrm{SD} \pm 14.4 \%)$ at $1.0 \mathrm{~m}$ deep, during midday on cloudless days. At the BRE site, it was $80.5 \%$ ( $\pm 10.0 \%)$ at $0.5 \mathrm{~m}$ and $48.2 \%( \pm 4.9 \%)$ at $1.0 \mathrm{~m}$ deep during midday on cloudless days. The water temperature was measured at both culture depths during sampling using a YSI 556 MPS meter. The temperature was similar at both sites and at both culture depths. The water temperature from July to September was $22-24^{\circ} \mathrm{C}$ and started to drop below $20^{\circ} \mathrm{C}$ in October and reached below $13^{\circ} \mathrm{C}$ in early November. Water samples $(\mathrm{n}=3)$ were also collected adjacent to the longlines at $1.0 \mathrm{~m}$ and then transferred to the laboratory in a cooler within $2 \mathrm{~h}$. The samples were filtered through $0.45 \mu \mathrm{m}$ glass microfiber filters (Whatman, Buckinghamshire, UK) and kept at $-20^{\circ} \mathrm{C}$ until measurements were made. Inorganic nutrients were analyzed using a SmartChem Discrete Analyzer (Unity Scientific, LLC, Brookfield, CT, USA). Nitrogen and phosphorus concentrations in the water column at the LIS site during the month of July 2011 ranged for $2.7-3.4 \mu \mathrm{mol} \mathrm{L}^{-1}$ and $0.9-1.2 \mu \mathrm{mol} \mathrm{L}^{-1}$, respectively. The nitrogen and phosphorus concentrations at this site started to increase from late August and were as high as 8.4 and $4.7 \mu \mathrm{mol} \mathrm{L}^{-1}$, respectively. The nutrient concentrations 
at the BRE site were significantly higher than those at the LIS site (37-55 $\mu \mathrm{mol} \mathrm{L}^{-1}$ of nitrogen and $14-19 \mu \mathrm{mol} \mathrm{L}^{-1}$ of phosphorus, respectively, during the months of August through October 2011).

\subsection{Agar extraction and purification}

Agar was hot-water extracted from the dried biomass using previously optimized conditions (Villanueva et al., 2010). The dried seaweeds $(4 \mathrm{~g})$ were pre-treated with $200 \mathrm{~mL}$ of $\mathrm{NaOH} 6 \%(\mathrm{w} / \mathrm{w})$ at $85^{\circ} \mathrm{C}$ for $3.5 \mathrm{~h}$. The mixture was washed several times with tap water and neutralized with $200 \mathrm{~mL}$ of acetic acid $0.5 \%(\mathrm{w} / \mathrm{w})$ for $1 \mathrm{~h}$ at room temperature. The extraction was then performed with $200 \mathrm{~mL}$ distilled water at $85^{\circ} \mathrm{C}$ for $2 \mathrm{~h}$ and the mixture was filtered whilst still hot with a filter cloth $(100 \%$ cotton). Agar was recovered through a freezethawing process, washed, dehydrated with ethanol (96\%) and dried at $60{ }^{\circ} \mathrm{C}$ overnight. The obtained products were milled in a coffee grinder. Finally, agar samples were purified by heat solubilization at $0.2 \%(\mathrm{w} /$ w) followed by centrifugation in a Beckman Coulter Allegra 25R centrifuge $\left(40^{\circ} \mathrm{C}, 21000 \times g\right.$ for $\left.1 \mathrm{~h}\right)$ and dried at $60^{\circ} \mathrm{C}$.

\subsection{Gel strength}

Agar $(1.5 \% \mathrm{w} / \mathrm{w})$ was solubilized with distilled water at boiling temperature until complete dissolution. $15 \mathrm{~g}$ of the hot solution were poured into a cylindrical container with $30 \mathrm{~mm}$ diameter covered and allowed to rest at room temperature for ca. $20 \mathrm{~h}$. A texture analyzer (TA-XT2 from Stable Micro Systems, Surrey, England) equipped with a cylindrical probe with $10 \mathrm{~mm}$ diameter was used for the gel strength determination. The rate of penetration was set at $0.2 \mathrm{~mm} / \mathrm{s}$ and the experiment was performed at least in triplicate for each agar sample. Gel strength was considered to be the stress required for breaking the gel surface, with the test parameters used.

\subsection{Gelling and melting temperatures}

Agar $(1.5 \% \mathrm{w} / \mathrm{w})$ was solubilized with distilled water at boiling temperature until complete dissolution. Gelling and melting temperatures were measured in a controlled stress rheometer AR-G2 (TA Instruments, New Castle, USA) fitted with a parallel cross hatched plate geometry $(40 \mathrm{~mm}$ diameter, gap $1000 \mu \mathrm{m})$. The solution was de-gassed and poured onto the pre-heated plate of the rheometer. Liquid paraffin oil was used to prevent water loss. A temperature ramp from 80 to $20^{\circ} \mathrm{C}$ at the rate of $2{ }^{\circ} \mathrm{C} / \mathrm{min}$ was applied. The sample was equilibrated for $30 \mathrm{~min}$ at $20^{\circ} \mathrm{C}$ and heated from 20 to $95^{\circ} \mathrm{C}$ with the same rate of $2{ }^{\circ} \mathrm{C} /$ min. Storage and viscous moduli were recorded at the end of the equilibration time at $20^{\circ} \mathrm{C}$. All experiments were performed with a frequency of $6.28 \mathrm{rad} / \mathrm{s}$ and $1.0 \%$ strain. Preliminary strain sweep tests were performed to ensure that the used strain was within the linear visco-elastic region.

\subsection{Chemical analyses}

Sulfate content was estimated by turbidimetry using the method with $\mathrm{BaCl}_{2}$ after hydrolysis, as described by Jackson and McCandless (1978). Agar samples (approx. $20 \mathrm{mg}$ ) were pre-hydrolyzed in $10 \mathrm{~mL}$ $\mathrm{HCl}$ of $1 \mathrm{~mol} / \mathrm{L}$ concentration and subsequently diluted to a final volume of $50 \mathrm{~mL}$. The precipitating reagent was then added to the samples and the optical density read at a wavelength of $500 \mathrm{~nm}$ using a UV/Vis spectrometer (Jasco, V-630 Bio). Sulfate standards were prepared with sodium sulfate at final concentrations ranging from 0.002 to $0.09 \%(\mathrm{w} /$ w) and treated in the same manner as the hydrolyzed samples. The 3,6anhydro-L-galactose content $(3,6-\mathrm{AG})$ was determined through the resorcinol-acetal colorimetric method (Yaphe \& Arsenault, 1965). Dfructose was used as standard. All chemical determinations were made in triplicate.

\subsection{Structure}

The samples with highest and lowest gelling ability were further characterized through Nuclear Magnetic Resonance spectroscopy (NMR), attenuated total reflectance Fourier-transform infrared spectroscopy (ATR-FTIR) and intrinsic viscosity measurements. The microstructure of their gels was imaged by Scanning Electron Microscopy (SEM).

The NMR experiments were carried out at CEMUP (Centro de Materiais da Universidade do Porto, Porto, Portugal) following a procedure described elsewhere (Sousa et al., 2013). All spectra (1H, 13C and $1 \mathrm{H}-13 \mathrm{C}$ correlations recorded through a phase-sensitive HSQC (heteronuclear single quantum coherence)) were acquired non-spinning at $80^{\circ} \mathrm{C}$ in a $400 \mathrm{MHz}$ Bruker Avance III spectrometer and using a $5 \mathrm{~mm}$ QNP probe equipped with a $\mathrm{z}$ gradient coil. The purified agar powders were dissolved in $\mathrm{D} 2 \mathrm{O}$ to a final concentration of $15 \mathrm{mg} / \mathrm{mL}$ and using TSP as internal reference $(\delta \mathrm{H}=-0.017 \mathrm{ppm} ; \delta \mathrm{C}=-0.18 \mathrm{ppm})$. For details on the acquisition parameters as well as the shorthand notation used for the chemical nomenclature of agar units (i.e. 3,6-anhydro- $\alpha$-Lgalactose, LA; 6-O-methyl- $\beta$-D-galactose, G6M; 2-O-methyl-3,6-anhydro- $\alpha$-L-galactose, LA2M; $\alpha$-L-galactose 6 -sulfate, L6S) previous papers can be consulted (Sousa et al., 2010, 2013).

The FTIR spectra of extracted agars were recorded using an ALPHA FTIR Spectrometer (Bruker, USA), by acquiring 60 scans with $4 \mathrm{~cm}^{-1}$ resolution.

A Cannon-Fenske viscometer for transparent liquids (according to ASTM D-2515) was used to measure intrinsic viscosities $([\eta] ; \mathrm{mL} / \mathrm{g}$ ) following the procedure described by Sousa et al., 2012. Diluted agar solutions were prepared using $0.75 \mathrm{~mol} / \mathrm{L} \mathrm{NaSCN}$ to inhibit agar aggregation. Concentrations were set to obtain relative viscosities from 1.2 to 2.0 (approximately), to allow linear regression according to Huggins and Kraemer relations, and extrapolation to zero. Viscosity average molecular weight (Mv) for each agar sample was calculated using the Mark-Houwink relationship (Rochas \& Lahaye, 1989):

$[\eta]=0.07 M_{v}^{0.72}$

The microstructure of the agar gels was confirmed by Cryogenic Scanning Electron Microscopy (CryoSEM) at CEMUP. For each sample, a small volume of the gel (approx. $1-3 \mathrm{~mm}^{3}$ ) was frozen in slushy nitrogen $\left(-210^{\circ} \mathrm{C}\right)$, transferred to an ALTO 2500 cryo-preparation chamber and placed onto a cool stage $\left(-150^{\circ} \mathrm{C}\right)$, where it was fractured exposing the internal surface. The ice formed on the exposed fractured surface was removed by sublimation at $-90^{\circ} \mathrm{C}$ for $1.5 \mathrm{~min}$. The sample was then sputter-coated with an $\mathrm{Au}-\mathrm{Pd}$ thin film at $-150{ }^{\circ} \mathrm{C}$ for $40 \mathrm{~s}$, from a sputter head using ultra-pure argon gas. The analysis was performed at $-150^{\circ} \mathrm{C}$ in a JEOL JSM 6301F scanning electron microscope equipped with a Gatan ALTO 2500 cryo-preparation chamber using an accelerating voltage of $15 \mathrm{kV}$ and working distances (WD) of $15 \mathrm{~mm}$.

\subsection{Thermal behavior}

The thermal properties of agar samples were assessed through differential Scanning Calorimetry using a PerkinElmer DSC 6000. Samples were cooled to $-20^{\circ} \mathrm{C}$, heated up to $160^{\circ} \mathrm{C}$, cooled back to $-20^{\circ} \mathrm{C}$ and re-heated up to $200^{\circ} \mathrm{C}$, at a heating or cooling rate of $10^{\circ} \mathrm{C} / \mathrm{min}$. At least two replicates were made for each sample.

Thermal gravimetric analyses were performed in a PerkinElmer TGA 4000 (PerkinElmer, Massachusetts, EUA). Samples were heated from $25^{\circ} \mathrm{C}$ to $600^{\circ} \mathrm{C}$ at a heating rate of $10^{\circ} \mathrm{C} / \mathrm{min}$ under a nitrogen atmosphere. At least two replicates were made for each sample.

\subsection{The properties of agar-based films}

Film forming solutions were prepared by heating $1.5 \%$ agar 
solutions up to $95^{\circ} \mathrm{C}$ and the temperature was kept for $30 \mathrm{~min}$, until complete dissolution. Samples were left to cool to $70{ }^{\circ} \mathrm{C}$, and glycerol was added as plasticizer to a final content of $0.15 \mathrm{~g} / \mathrm{g}_{\text {dry agar. }} 40 \mathrm{~g}$ of each film-forming solution were poured into polyoxyethylene methylene (POM) petri dishes with a diameter of $12 \mathrm{~cm}$. Films were dried at $40^{\circ} \mathrm{C}$ for $18 \mathrm{~h}$ and equilibrated for $48 \mathrm{~h}$ at $53 \% \mathrm{RH}$, in a desiccator at $20^{\circ} \mathrm{C}$ with a saturated salt solution of $\mathrm{Mg}\left(\mathrm{NO}_{3}\right)_{2}$, before further analyses.

Film thickness was measured with a digital micrometer (No. 293-561, Mitutoyo, Japan) at 6 random positions for each film.

Tensile strength (TS) and elongation at break (EB) were determined in a TA. HDplus texture analyzer (Stable MicroSystems) equipped with tensile test attachments, following the guidelines of ASTM D882-91 standard method, as described by Costa et al., 2018. The tests were replicated eight times.

Water vapor permeability (WVP) was measured gravimetrically according to ASTM E96-92 standard test. The equilibrated films were sealed tightly to a permeation cell containing distilled water $(100 \%$ relative humidity $(\mathrm{RH})$ ) and placed inside a desiccator with silica gel $(0 \% \mathrm{RH})$. Weight loss was monitored every $2 \mathrm{~h}$ for $10 \mathrm{~h}$. Testing was performed in triplicate. WVP was calculated by linear regression, using Eq. (2), as described by Silva, Mauro, Goncalves, \& Rocha, 2016:

$W V P=\frac{\Delta m \times x}{\Delta P \times A \times t}$

$\Delta m$ represents the weight loss $(\mathrm{g}), \mathrm{x}$ is the average film thickness (m), $A$ is the permeation area, $t$ is duration (s) and $\Delta P$ is the difference of the water vapor partial pressure at $20^{\circ} \mathrm{C}(2337 \mathrm{~Pa})$ between the two sides of film. Three replicates were made.

\subsection{Statistical analyses}

All statistical analyses were made using the data analysis software Statistica version 8.0 (StatSoft, Inc, Tulsa, OK, USA). The influence of time (random) and depth (fixed, two levels) on yield, gel strength, sulfate and 3,6-anhydro- $\alpha$-L-galactose contents were analyzed by factorial analysis of variance (ANOVA). A separate analysis was made for location (fixed, two levels), including also time (only samples from October and November) and depth (fixed, two levels), as data were more limited for the BRE site. For significant differences from ANOVA, variances were tested for homogeneity and statistically significant differences were analyzed a posteriori with Scheffé's multiple comparisons test. The significance level was defined as $\mathrm{p} \leq 0.05$, for all tests.

\section{Results and discussion}

Results obtained for agar extracted from Gracilaria tikvahiae are presented in Tables 1-5 and Figs. 1-8. Gracilaria was collected in the summer and fall of 2011. The extraction conditions were based on early optimization studies concerning G. vermiculophylla from the Portuguese coast (Villanueva et al., 2010).

\subsection{Yield, gel strength and physico-chemical properties}

Yields for LIS samples after the purification step (Fig. 1) ranged from 13 to $17 \%$ (15-19\% prior to purification). A wide range of extraction yields can be found in the literature, due to different seaweeds and extraction protocols applied, but yield values of near $20 \%$ are frequently reported for pre-treated agar from different Gracilaria spp. without re-extraction steps (e.g. Arvizu-Higuera et al., 2008; Lewis \& Hanisak, 1996; Skriptsova \& Nabivailo, 2009; Villanueva et al., 2010). Nevertheless, extraction yields below $10 \%$ were reported for G. tikvahiae (Lopezbautista \& Kapraun, 1995), making the yields achieved in this work significant. However, the low yield reported by Lopezbautista \& Kapraun was obtained in July, with very high water temperatures (ca. $30^{\circ} \mathrm{C}$ ). Yields for the BRE samples were significantly lower than those from LIS samples in October and November and ranged from 11 to $12 \%$ (Figs. 1 and 2). No significant differences were observed in agar yields between Gracilaria cultivated at different depths at each site. Overall extraction yields unrelated with light intensity were also reported for Gelidium pulchellum (Sousa-Pinto, Murano, Coelho, Felga, \& Pereira, 1999), though higher amounts of agar with a lower melting point were extracted with increased irradiance.

At the LIS site, seasonal variations were significant (Table 1), the yield being higher during August which generally decreased until November (Fig. 1). From the literature, these results with higher yields in summer and steep decreases in autumn and winter were expected for sites within a temperate climate (e.g. Marinho-Soriano and Bourret (2003), for Gracilaria bursa-pastoris and Martin et al. (2013), for G. gracilis). Slight seasonal differences in yield and strong seasonal differences in gel strengths were also reported for agars from G. tikvahiae (Bird \& Hinson, 1992). The yield of agar has often been positively correlated with temperature and salinity and negatively with nitrogen content, as reported for G. bursa-pastoris (Marinho-Soriano \& Bourret, 2003) or G. gracilis (Martin et al., 2013). With the decrease of nitrogen, for instance, protein synthesis decreases in favor of polysaccharide synthesis. Water temperature was higher at the beginning of August, and decreased slightly until the beginning of October and declined sharply after that. The tissue nitrogen content started to increase also from late August at the LIS site. Differences in nitrogen content and salinity may also justify the differences in agar yield between both sites: BRE had considerable higher nitrogen content and slightly lower salinity, leading to concomitant lower yields.

Seasonal differences in the gel strength were also statistically significant (Fig. 3; Table 1). With the exception of some samples from late October and November, all samples presented acceptable GS (from 580 to $893 \mathrm{~g} / \mathrm{cm}^{2}$ ). This gel strength was in fact higher than that in another study using the same species (Lopezbautista \& Kapraun, 1995). Another statistical analysis was made excluding the out-lying October and November samples, when temperature started decreasing sharply. In this new statistical analysis, differences in GS at different depths became significant (Table 1), particularly for samples in September and early October. This result may be related with faster temperature variations (drops) near the surface (at $0.5 \mathrm{~m}$ ).

Gel strength was highest in September and lowest in late October and early November (Fig. 3). For Gracilaria at $1.0 \mathrm{~m}$, values in November $\left(610 \mathrm{~g} / \mathrm{cm}^{2}\right)$ were similar to values at mid-August $\left(580 \mathrm{~g} / \mathrm{cm}^{2}\right)$. The growth rate of another Gracilaria (Gracilaria multipartita) has been negatively correlated with agar gel strength (Givernaud, El Gourji, Mouradi-Givernaud, Lemoine, \& Chiadmi, 1999), with the GS decreasing from February to July; increasing from August to October, decreasing in November-December and increasing again in January and February, on the Atlantic coast of Morocco. The results obtained at LIS and BRE are similar, with the autumn decrease in growth rate starting slightly earlier, due to the colder climate at these sites in comparison to Morocco.

Light has been inversely correlated in the literature with increasing gel strength (Villanueva, Hilliou, \& Sousa-Pinto, 2009). However, the present study showed that the Gracilaria grown at $0.5 \mathrm{~m}$ had a higher GS than the same seaweed grown at $1.0 \mathrm{~m}$ during summer (Fig. 3). In autumn, however, no defined trend was observed: the samples from LIS in late October and November had higher a GS at $1.0 \mathrm{~m}$ (lower light intensity), and the samples from BRE and LIS in the beginning of October had a higher GS when grown at $0.5 \mathrm{~m}$. Nevertheless, as the seaweeds were cultivated in open-water farms, weather may be governing the differences, being the seaweeds cultivated nearer the surface more vulnerable to weather changes.

Temperature decreased slowly from August to early October. From late October, a steep decrease was observed at both cultivation sites (Kim et al., 2014). This together with high variations in diffuse attenuation coefficients (with different trends at each site) may have been responsible for the inconsistent results in the values of GS during this 
Table 1

Results from the statistical analyses (ANOVA and Scheffé's test (main differences).

\begin{tabular}{|c|c|c|c|c|}
\hline & Yield & GS & Sulfate & 3,6-AG \\
\hline \multicolumn{5}{|c|}{ From Aug to Nov } \\
\hline Depth & Not significant & Not significant & Significant & Significant \\
\hline Seasonality & Significant & Significant & Significant & Significant \\
\hline Scheffé's test & $\begin{array}{l}\text { Different in August and late } \\
\text { autumn }\end{array}$ & $\begin{array}{l}\text { Different in late August, September and } \\
\text { November }\end{array}$ & Different in August and late October & $\begin{array}{l}\text { Different at } 0.5 \mathrm{~m} \text { in late } \\
\text { August }\end{array}$ \\
\hline \multicolumn{5}{|c|}{ From Aug to early Oct } \\
\hline Depth & Not significant & Significant & Significant & Significant \\
\hline Seasonality & Significant & Significant & Significant & Significant \\
\hline Scheffé's test & Different in August and October & $\begin{array}{l}\text { Different also in September, at different } \\
\text { depths }\end{array}$ & Different at $0.5 \mathrm{~m}$ in September and October & $\begin{array}{l}\text { Different at } 0.5 \mathrm{~m} \text { in late } \\
\text { August }\end{array}$ \\
\hline \multicolumn{5}{|c|}{ From Oct to Nov } \\
\hline Location & Significant & Not significant & Significant & Significant \\
\hline Depth & Not significant & Not significant & Significant & Not significant \\
\hline Seasonality & Significant & Significant & Significant & Significant \\
\hline Scheffé's test & Only different for site location & Different in early October & $\begin{array}{l}\text { Different in late October }(0.5 \text { and } 1 \mathrm{~m}) \text { and } \\
\text { November }(1 \mathrm{~m})\end{array}$ & Different at $1 \mathrm{~m}$ in November \\
\hline
\end{tabular}

last tested period.

Though depth of cultivation seemed to have an effect opposite to the expected in gel strength, this did not happen with 3,6-AG and sulfate contents (Fig. 4). In fact, at least until early October, the sulfate content was globally higher when biomass was grown at the shallower depths (and higher light intensities) and the 3,6-AG content seemed to be globally lower from material cultivated at the shallower depths. It has been often reported that darkness has a negative effect on sulfate content and a positive effect on 3,6-AG content. For instance, it was reported that a 10 days dark post-harvest treatment of Chondrus improved the gelling properties of the extracted carrageenan through the decrease in sulfate and increase in 3,6-AG content, in a similar way to the alkali extraction pre-treatment (Villanueva et al., 2009).

This probably means that, in spite of the effect of darkness on 3,6AG and sulfate contents, other factors were also conditioning agar performance, such as sulfate position, molecular weight, other substituent groups (such as methyl) and/or the presence of other storage polysaccharides (e.g. floridean starch). Furthermore, despite the alkali pre-treatment, the sulfate content was still moderate and no relationship was found between differences in the contents of sulfate and 3,6AG. Therefore the sulfate groups were probably not mainly in the form
Table 3

Chemical shifts assignments by ${ }^{1} \mathrm{H}$ NMR for alkali-treated agar.

\begin{tabular}{llllll}
\hline & $\begin{array}{l}\text { Ref. Shifts (ppm) } \\
\text { (Villanueva et al., } \\
\text { 2010) }\end{array}$ & $\begin{array}{l}\text { LIS 9-15; } \\
1 \mathrm{M}\end{array}$ & $\begin{array}{l}\text { LIS 9-15; } \\
0.5 \mathrm{M}\end{array}$ & $\begin{array}{l}\text { LIS 11-04; } \\
1 \mathrm{M}\end{array}$ & $\begin{array}{l}\text { BRE 11-02; } \\
1 \mathrm{M}\end{array}$ \\
\hline G1 & 4.55 & 4.54 & 4.54 & 4.55 & 4.54 \\
G2 & 3.63 & 3.62 & 3.62 & 3.63 & 3.62 \\
G3 & 3.76 & 3.76 & 3.76 & 3.75 & 3.76 \\
G4 & 4.11 & 4.11 & 4.11 & 4.12 & 4.10 \\
G5 & 3.69 & 3.66 & 3.67 & 3.67 & 3.67 \\
G6 & $3.73(1) / 3.79(2)$ & $3.75 / 3.82$ & $3.73 / 3.81$ & $3.68 / 3.83$ & $3.68 / 3.82$ \\
G6M & 3.41 & 3.40 & 3.41 & 3.41 & 3.41 \\
LA1 & 5.13 & 5.12 & 5.13 & 5.13 & 5.13 \\
LA2 & 4.11 & 4.11 & 4.11 & 4.12 & 4.10 \\
LA3 & 4.55 & 4.54 & 4.54 & 4.55 & 4.54 \\
LA4 & 4.65 & 4.65 & 4.65 & 4.65 & 4.65 \\
LA5 & 4.55 & 4.54 & 4.54 & 4.55 & 4.54 \\
LA6 & $4.02(3) / 4.24(4)$ & $4.02 / 4,29$ & $4.02 / 4,28$ & $4.03 / 4.24$ & $4.04 / 4.24$ \\
LA2M & 3.52 & 3.51 & 3.51 & 3.52 & 3.51 \\
L6S & 5.28 & n.d. & n.d. & 5.21 & 5.21 \\
\hline
\end{tabular}

n.d. not discernible.

Table 2

Rheological data obtained through dynamic rheological measurements in a stress-controlled rheometer for agar from two sites and two different depths from August to November (storage modulus, G'; viscous modulus, G”; gelling temperature, Tg; melting temperature, Tm; mean \pm SD).

\begin{tabular}{|c|c|c|c|c|c|c|}
\hline & Depth (m) & Date & $\mathrm{G}^{\prime}(\mathrm{Pa})$ & G" (Pa) & $\operatorname{Tg}\left({ }^{\circ} \mathrm{C}\right)$ & $\operatorname{Tm}\left({ }^{\circ} \mathrm{C}\right)$ \\
\hline LIS & 1.0 & $8-16-11$ & $9617 \pm 5$ & $129 \pm 6$ & $47.9 \pm 0.3$ & $89.7 \pm 0.5$ \\
\hline LIS & 0.5 & 8-16-11 & $12860 \pm 113$ & $252 \pm 20$ & $48.7 \pm 0.1$ & $90.2 \pm 0.7$ \\
\hline LIS & 0.5 & $8-26-11$ & $12375 \pm 1379$ & $226 \pm 29$ & $47.2 \pm 0.3$ & $89.5 \pm 0.6$ \\
\hline LIS & 1.0 & $8-26-11$ & $11690 \pm 622$ & $162 \pm 1$ & $47.1 \pm 0.1$ & $90.4 \pm 0.1$ \\
\hline LIS & 0.5 & $9-15-11$ & $16780 \pm 240$ & $315 \pm 2$ & $45.8 \pm 0.1$ & $89.0 \pm 0.1$ \\
\hline LIS & 1.0 & $9-15-11$ & $13070 \pm 1174$ & $268 \pm 10$ & $45.6 \pm 0.3$ & $90.9 \pm 0.9$ \\
\hline LIS & 0.5 & $10-7-11$ & $14043 \pm 2397$ & $283 \pm 33$ & $46.7 \pm 0.4$ & $89.7 \pm 1.3$ \\
\hline LIS & 1.0 & $10-7-11$ & $10860 \pm 240$ & $164 \pm 4$ & $48.6 \pm 0.4$ & $89.3 \pm 0.5$ \\
\hline LIS & 0.5 & $10-24-11$ & $14624 \pm 2214$ & $315 \pm 51$ & $44.9 \pm 0.3$ & $90.4 \pm 1.5$ \\
\hline LIS & 1.0 & $10-24-11$ & $11564 \pm 984$ & $276 \pm 20$ & $45.8 \pm 0.6$ & $90.7 \pm 0.5$ \\
\hline LIS & 1.0 & $11-4-11$ & $13500 \pm 1004$ & $261 \pm 24$ & $46.7 \pm 0.4$ & $88.1 \pm 0.3$ \\
\hline LIS & 0.5 & $11-4-11$ & $13710 \pm 42$ & $246 \pm 2$ & $45.2 \pm 0.1$ & $83.3 \pm 0.4$ \\
\hline BRE & 0.5 & $10-5-11$ & $14890 \pm 2263$ & $281 \pm 16$ & $46.4 \pm 0.1$ & $87.8 \pm 1.6$ \\
\hline BRE & 1.0 & $10-5-11$ & $12405 \pm 148$ & $235 \pm 45$ & $47.1 \pm 0.4$ & $85.3 \pm 0.4$ \\
\hline BRE & 1.0 & $10-19-11$ & $12530 \pm 679$ & $250 \pm 22$ & $46.5 \pm 0.6$ & $87.8 \pm 0.5$ \\
\hline BRE & 0.5 & $10-19-11$ & $16430 \pm 1372$ & $311 \pm 11$ & $45.3 \pm 0.8$ & $87.4 \pm 3.1$ \\
\hline BRE & 1.0 & $11-2-11$ & $11440 \pm 184$ & $187 \pm 6$ & $47.0 \pm 0.1$ & $83.0 \pm 0.1$ \\
\hline BRE & 0.5 & $11-2-11$ & $15850 \pm 764$ & $301 \pm 9$ & $45.6 \pm 0.3$ & $86.0 \pm 1.5$ \\
\hline
\end{tabular}


Table 4

Thermal properties and molecular weight.

\begin{tabular}{|c|c|c|c|c|}
\hline & LIS 9-15; 1M & LIS 9-15; 0.5M & LIS 11-04; 1M & BRE 11-02; 1M \\
\hline Mv (kDa) & 338 & 302 & 180 & 131 \\
\hline $\mathrm{T}_{1}\left({ }^{\circ} \mathrm{C}\right)$ & n.d. & $98.5 \pm 0.1$ & $93.7 \pm 0.9$ & 97.7 \\
\hline $\mathrm{T}_{2}\left({ }^{0} \mathrm{C}\right)$ & n.d. & $131 \pm 1$ & $128 \pm 1$ & 126 \\
\hline $\mathrm{T}_{3}\left({ }^{0} \mathrm{C}\right)$ & $136 \pm 7$ & $138 \pm 3$ & $139 \pm 7$ & $138 \pm 1$ \\
\hline$\Delta \mathrm{H}_{3}(\mathrm{~J} / \mathrm{g})$ & $246 \pm 37$ & $172 \pm 10$ & $191 \pm 11$ & $232 \pm 63$ \\
\hline $\mathrm{T}_{\text {glass }}\left({ }^{\circ} \mathrm{C}\right)$ & $22.8 \pm 0.1$ & $22.7 \pm 0.3$ & $22.6 \pm 0.1$ & $22.7 \pm 0.1$ \\
\hline$c_{p}\left(J /\left(g^{0} \mathrm{C}\right)\right.$ & $0.0345 \pm 0.008$ & $0.0485 \pm 0.005$ & $0.0410 \pm 0.002$ & $0.0395 \pm 0.006$ \\
\hline $\begin{array}{l}\text { Water content (\%) } \\
\text { (TGA) }\end{array}$ & $15.1 \pm 0.2$ & $15.7 \pm 1.4$ & $16.1 \pm 0.5$ & $16.7 \pm 0.4$ \\
\hline Tsd & $197 \pm 8$ & $197 \pm 3$ & $211 \pm 9$ & $206 \pm 1$ \\
\hline $\mathrm{Td}$ & $277 \pm 2$ & $283 \pm 2$ & $289 \pm 1$ & $239 \pm 1$ \\
\hline
\end{tabular}

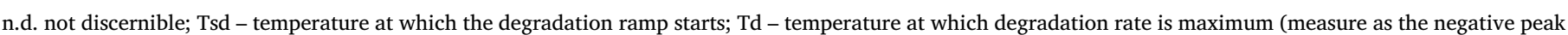
in the first derivative curve).

of L6S (Givernaud et al., 1999).

Rheological parameters for various agar gels are presented in Table 2. The storage or elastic modulus $\left(\mathrm{G}^{\prime}\right)$ is a measure of the solid nature of a sample and is expected to be positively correlated with the gel strength. In fact, G' at $20^{\circ} \mathrm{C}$ followed a similar trend to the gel strength, being highest in September. The storage modulus was significantly different at different depths being consistently higher at 0.5 $\mathrm{m}$, confirming the general trend of GS (with the exceptions in GS referred above). Site differences were not visible. Melting temperatures of around $90^{\circ} \mathrm{C}$ (Table 2) are typical of agar samples suitable as agar standards (Arvizu-Higuera et al., 2008) according to the United States Pharmacopeia (USP) criteria $\left(\mathrm{Tm}>85^{\circ} \mathrm{C}\right)$. Differences related to depth and seasonality were only significant in November. Agars from the LIS site presented slightly higher melting temperature than agars from BRE (with higher nitrogen content). Gelling temperatures were slightly higher than the typical gelling temperatures of commercial agars, which are generally below $40^{\circ} \mathrm{C}$, but common in agar from Gracilaria sp., particularly if highly methylated. Despite the good gelling ability, the gel temperatures above $32-36{ }^{\circ} \mathrm{C}$ made these agars unsuitable for direct use in bacteriological grade applications (Skriptsova \& Nabivailo, 2009).

\subsection{NMR, FTIR and molecular weight}

The ${ }^{13} \mathrm{C}$ and ${ }^{1} \mathrm{H}$ chemical assignments of alkali-treated agars were obtained through NMR spectroscopy. The chemical shift assignments by ${ }^{1} \mathrm{H}$ NMR are presented in Table 3 . The 12 characteristic ${ }^{13} \mathrm{C}$ signals of agarose and the presence of substituent groups such as sulfate, O-methyl, pyruvic acid ketals, and other monosaccharides in the agar backbone were inspected at typical signals by comparison with previous studies on agar NMR characterization (Rodriguez, Matulewicz, Noseda, Ducatti, \& Leonardi, 2009; Villanueva et al., 2010).

The backbone substitutions, induced by physiological (i.e. during the life cycle of the alga) and environmental aspects (i.e. growth conditions, season of collection, cultivation site) as well as the extraction conditions, are crucial factors since they define the final properties of the polysaccharide. For instance, the alkaline treatment of agar causes the conversion of the $\alpha$-L-galactose 6-sulfate (L6S) in 4-linked 3,6-anhydro- $\alpha$-L-galactose (LA) units, leading to a significant increase in gel strength. L6S residues were detected through a minor peak $\sim 5.17 \mathrm{ppm}$ in the ${ }^{1} \mathrm{H}$ spectra and a minor cross-peak in the HSQC at $(\sim 5.17 ; 102.1)$

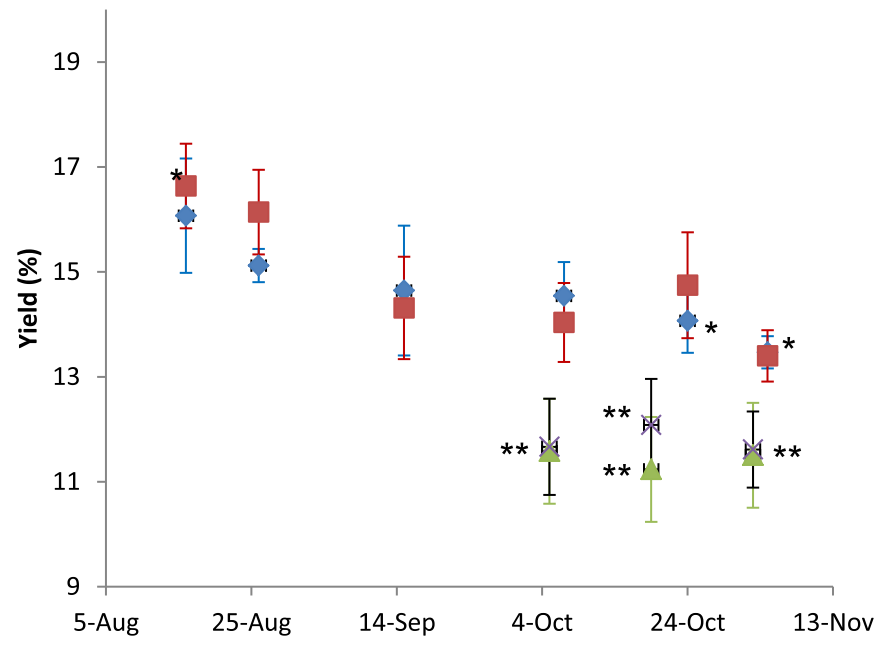

Fig. 1. Effective yield ( $g_{\text {purified extract }} / g_{\text {seaweed }}$ ): Long Island Sound $0.5 \mathrm{~m}$; Long Island Sound $1.0 \mathrm{~m}$; $\triangle$ Bronx River Estuary $0.5 \mathrm{~m}$; $\times$ Bronx River Estuary $1.0 \mathrm{~m}$ (* significant differences in seasonality; ** significant differences in site location), mean \pm SD.

ppm attributed to $\mathrm{H} 1$ and $\mathrm{C} 1$ of L6S, respectively. This peak was undetected in LIS September samples that showed the highest gel strength. The peak was still present (though very small) in BRE and LIS November samples, with the lowest gel strength. The persistence of this signal, after alkali treatment, indicated that these samples had originally more L6S groups (i.e. before the alkaline pre-treatment, in accordance with previous studies reporting higher sulfate content in the cold season (e.g. Romero et al., 2007).

Furthermore, samples isolated from biomass grown at both LIS and BRE sites in November presented a minor peak at $62.8\left({ }^{13} \mathrm{C}\right.$ spectra) that may correspond to amylose from contaminating floridean starch. This peak was absent from the September samples. Therefore, under the more adverse environmental conditions for seaweed growth, storage polysaccharide accumulation was starting to be relevant, as could be expected. Furthermore, the presence of the floridean starch may have been responsible for the differences the behavior between the rheological parameters (namely, storage and viscous moduli) and gel strength for the BRE samples and those from LIS in November. In fact, despite

Table 5

LIS agar's films properties.

\begin{tabular}{|c|c|c|c|}
\hline \multirow[t]{2}{*}{ Thickness (mm) } & \multicolumn{2}{|l|}{ Mechanical properties } & \multirow[t]{2}{*}{ WVP $(\mathrm{g} /(\mathrm{msPa}))$} \\
\hline & Tensile strength (MPa) & Elongation at break (\%) & \\
\hline $0.049 \pm 0.005$ & $16.8 \pm 1.2$ & $11.2 \pm 1.7$ & $2.6 \times 10^{-11} \pm 0.1 \times 10^{-11}$ \\
\hline
\end{tabular}




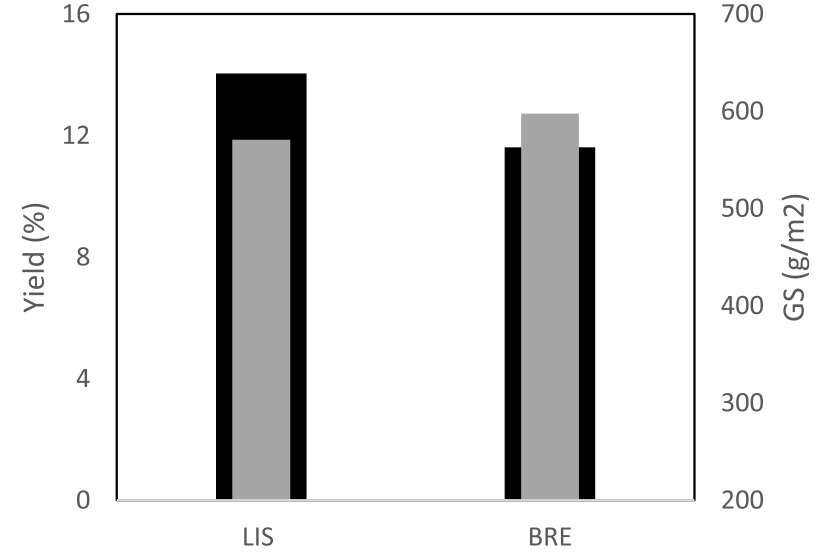

Fig. 2. Overall comparison of yield and GS between the two sites - Long Island Sound (LIS) and Bronx River Estuary (BRE) (only data from October and November was considered) - - Yield; $\square \mathrm{GS}$, mean \pm SD.

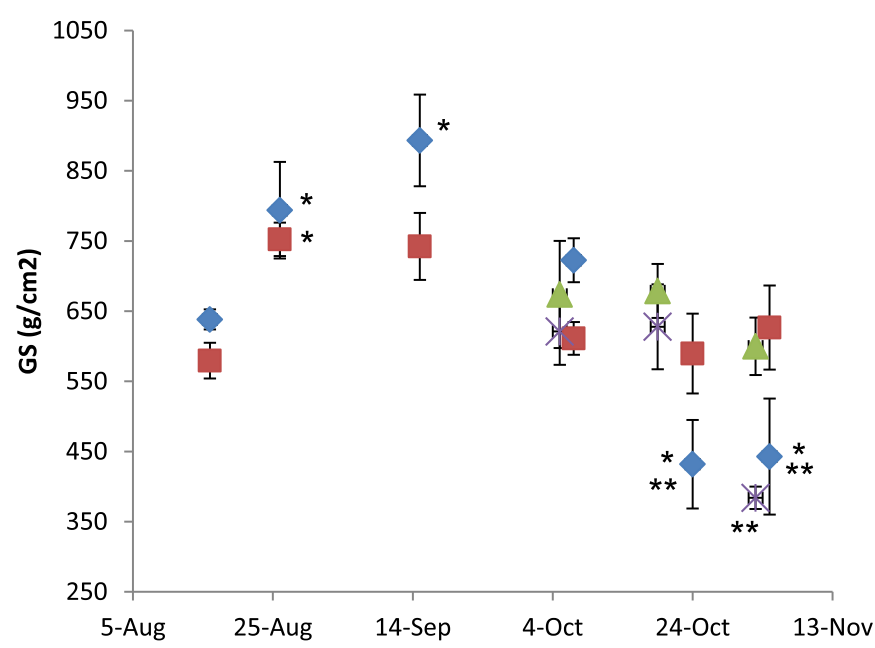

Fig. 3. Gel strength at two different sites and two different depths: Long Island Sound $0.5 \mathrm{~m}$; L Long Island Sound $1.0 \mathrm{~m}$; $\triangle$ Bronx River Estuary 0.5 $\mathrm{m}$; $\times$ Bronx River Estuary $1.0 \mathrm{~m}$ (* significant differences in seasonality; ** significant differences in site location), mean \pm SD.

the general decrease in the GS after September, storage and viscous moduli were higher. Floridean starch generally has a negative effect on the GS of agar (Rodriguez et al., 2009). An unidentified minor peak in the LIS November samples was present at $64.3\left({ }^{13} \mathrm{C}\right)$.

Nevertheless, overall the HSQC pattern was typical of agar samples in all cases (Fig. 5), with all characteristic signals from agarose being easily identified, confirming that this was the main extracted component. Overall samples presented significant degrees of methylation substitution at $\mathrm{C} 6$ of the $\mathrm{G}$ units, which was detected with the presence of a peak at about $60 \mathrm{ppm}$ in the ${ }^{13} \mathrm{C}$ spectra, due to the downshift in the nearest carbon resonance (Usov, 1984), and a sharp singlet at $3.41 \mathrm{ppm}$. The presence of methylated substituents was probably responsible for the high gelling temperature (above $45^{\circ} \mathrm{C}$ ), as they are known to raise the gel setting temperature. For instance, Falshaw, Furneaux, and Stevenson (1998) reported an increase in the melting temperature from 33 to $37^{\circ} \mathrm{C}$ for non-methylated agar samples to $42-49^{\circ} \mathrm{C}$ for naturally methylated material. The presence of 4-O-methyl-L-galactose has also been associated with the age of G. tikvahiae (Craigie \& Jurgens, 1989). In fact, these authors concluded that young tissues had only traces of 4O-methyl-L-galactose groups and that they were markedly present in the agar extracted from mature seaweeds. Therefore, the presence of significant methylation could be related with the age of the seaweeds, as G. tikvahiae thalli were harvested after some growth period.
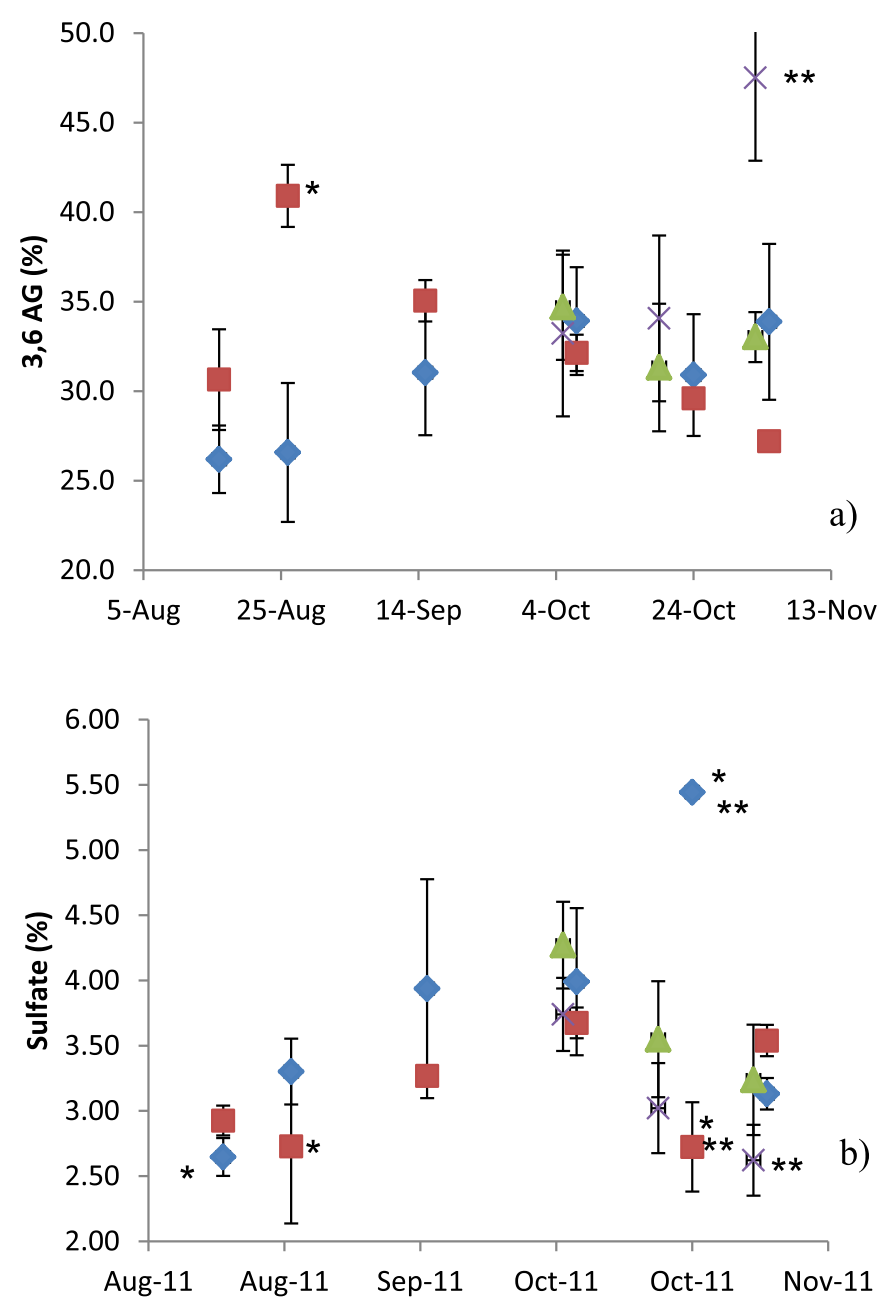

Fig. 4. Chemical properties of the extracted agar: a) 3,6-AG content; b) sulfate content; $\downarrow$ Long Island Sound $0.5 \mathrm{~m}$; - Long Island Sound $1.0 \mathrm{~m}$; $\triangle$ Bronx River Estuary $0.5 \mathrm{~m}$; $\times$ Bronx River Estuary $1.0 \mathrm{~m}$ (* significant differences in seasonality; ** significant differences in site location), mean \pm SD.

Methylation on the C2 of LA units, detected by the presence of small peaks in the region 3.51-3.52, was also observed but at a much lower extent. The LIS sample from November seemed to have a different pattern related to the methylated groups, namely the LA2M groups, with a more intense peak in the $1 \mathrm{D}{ }^{1} \mathrm{H}$ NMR spectra (Fig. 5 ; $3.51 \mathrm{ppm}$ ), when compared to the September LIS sample. This observation may be responsible for the differences in the $\mathrm{Tm}$. In fact, the $\mathrm{Tm}$ values for the LIS samples in November were significantly lower than that from the LIS samples taken in other months. Pyruvate residues were not found in any of the samples.

FTIR spectra are presented in Fig. 6 and generally confirmed the NMR results. Spectra of all samples were very similar and the typical bands for agar samples were easily identified: 1370 and $1250 \mathrm{~cm}^{-1}$ are referred to be related with total sulfate (ester sulfates and $\mathrm{S}=\mathrm{O}$ stretching vibration, respectively), $930 \mathrm{~cm}^{-1}$ is related with the $\mathrm{C}-\mathrm{O}$ vibration of LA units, (Sousa et al., 2012). The broad absorption region between 1100 and $1000 \mathrm{~cm}^{-1}$ as well as the band at $1150 \mathrm{~cm}^{-1}$ are common to all polysaccharides and could be assigned $\mathrm{C}-\mathrm{O}-\mathrm{H}$ bending and to $\mathrm{C}-\mathrm{O}$ and $\mathrm{C}-\mathrm{C}$ stretching (Warren, Perston, Royall, Butterworth, \& Ellis, 2013). The characteristic peak at $1640 \mathrm{~cm}^{-1}$ is assigned to $\mathrm{C}=$ O stretching (Selvalakshmi, Vijaya, Selvasekarapandian, \& Premalatha, 2017). The band at $890 \mathrm{~cm}^{-1}$ is also typical of agar samples and could be related with the $\mathrm{C}-\mathrm{H}$ bending at the anomeric carbon in $\mathrm{G}$ residues. The absence of peaks at 805 and $830 \mathrm{~cm}^{-1}$ indicated no sulfates at C2 in LA and G moieties, respectively, and the small shoulder at $850 \mathrm{~cm}^{-1}$ 


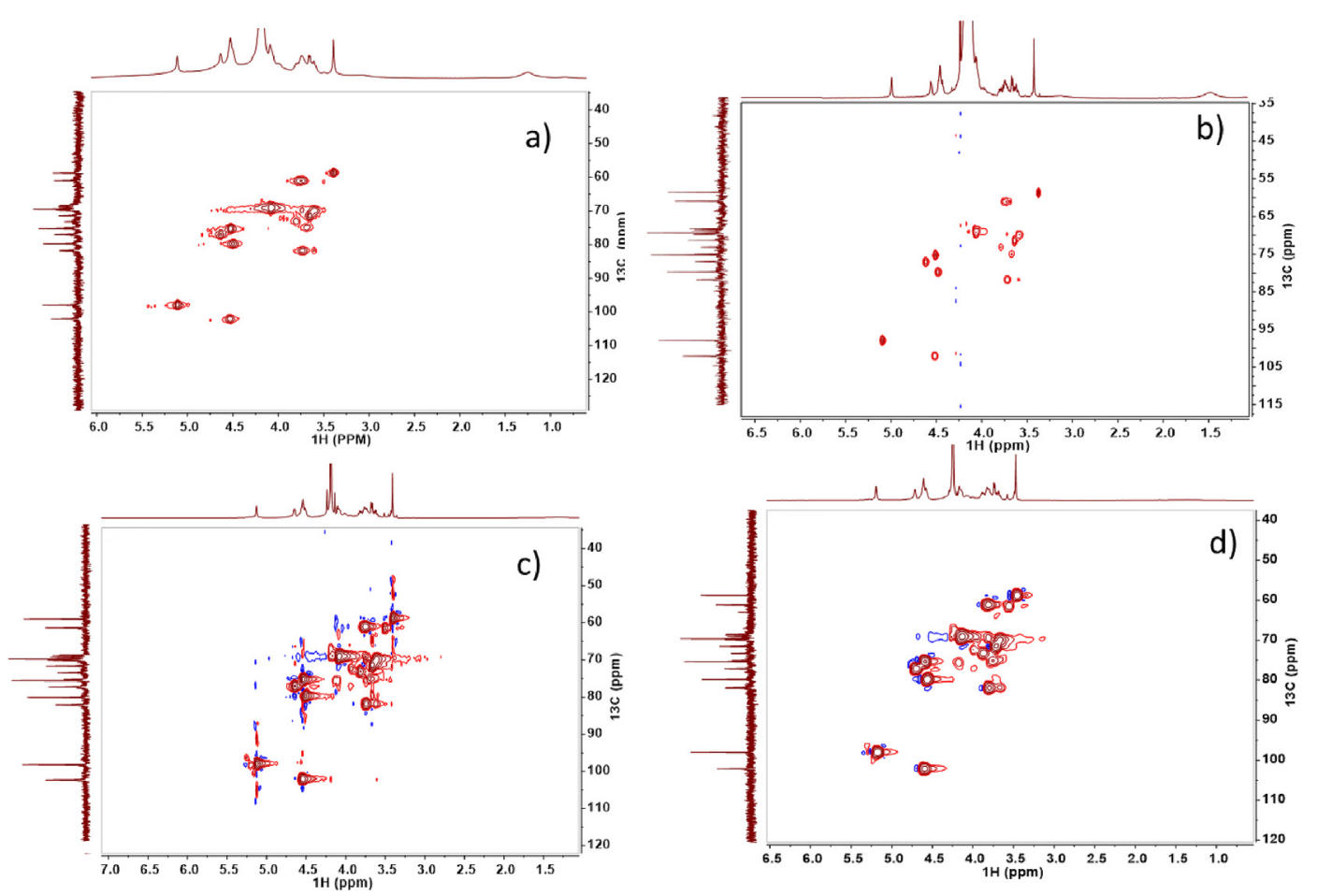

Fig. 5. HSQC spectra with the corresponding 1D NMR spectra of each nucleus for the alkali-treated agar from: a) Long Island Sound 0.5 m in 15/09; b) Long Island Sound $1.0 \mathrm{~m}$ in 15/09; c) Bronx River Estuary $1.0 \mathrm{~m}$ in 02/11; d) Long Island Sound $1.0 \mathrm{~m}$ in 04/11.

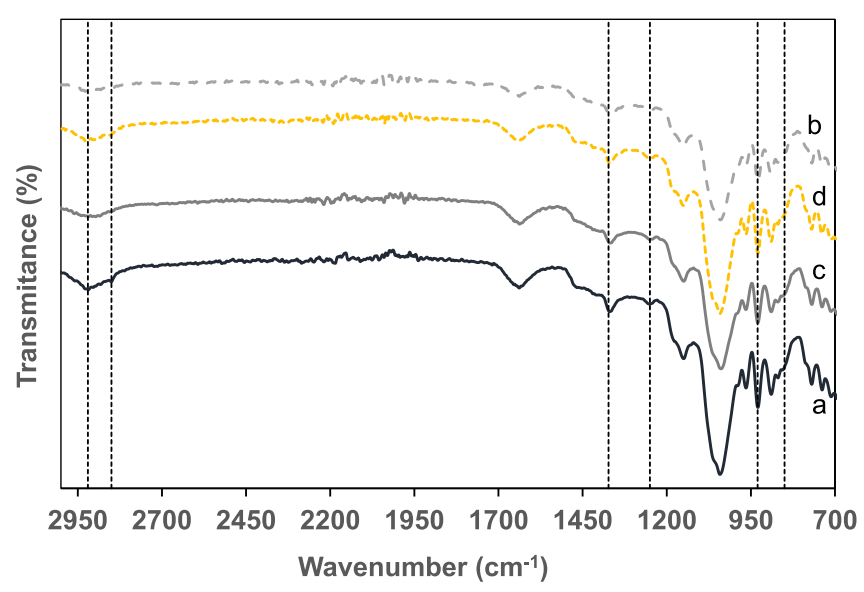

Fig. 6. FTIR spectra for the alkali-treated agar from: a) Long Island Sound $0.5 \mathrm{~m}$ in 15/09; b) Long Island Sound $1.0 \mathrm{~m}$ in 15/09; c) Bronx River Estuary $1.0 \mathrm{~m}$ in $02 / 11$; d) Long Island Sound $1.0 \mathrm{~m}$ in $04 / 11$.

indicated low amount of sulfates at C4 of G moieties (Romero, Villanueva, \& Montano, 2008). Furthermore, the absence of a band at $820 \mathrm{~cm}^{-1}$ indicated no or very low sulfates at C6 of G moieties (Rochas, Lahaye, \& Yaphe, 1986), as expected due to the alkali pre-treatment. Nevertheless, a small shoulder could be seen in the BRE sample, confirming the results from NMR. Bands at 740 and $770 \mathrm{~cm}^{-1}$ are related with skeletal bending of the galactose ring (Rhein-Knudsen, Ale, Ajalloueian, Yu, \& Meyer, 2017). Finally, the band at $2920 \mathrm{~cm}^{-1}$ is related with the $\mathrm{C}-\mathrm{H}$, being a good measure of total sugar content (Rochas et al., 1986). The small shoulder on this band at $2850 \mathrm{~cm}^{-1}$ is typical of highly methylated agars which is once more in accordance with NMR results.

In terms of molecular weight measurements, samples from September had a much higher viscosity average molecular weight than samples from November, as expected from the GS values. Furthermore samples from the BRE site had the lowest gelling strength. Depth of
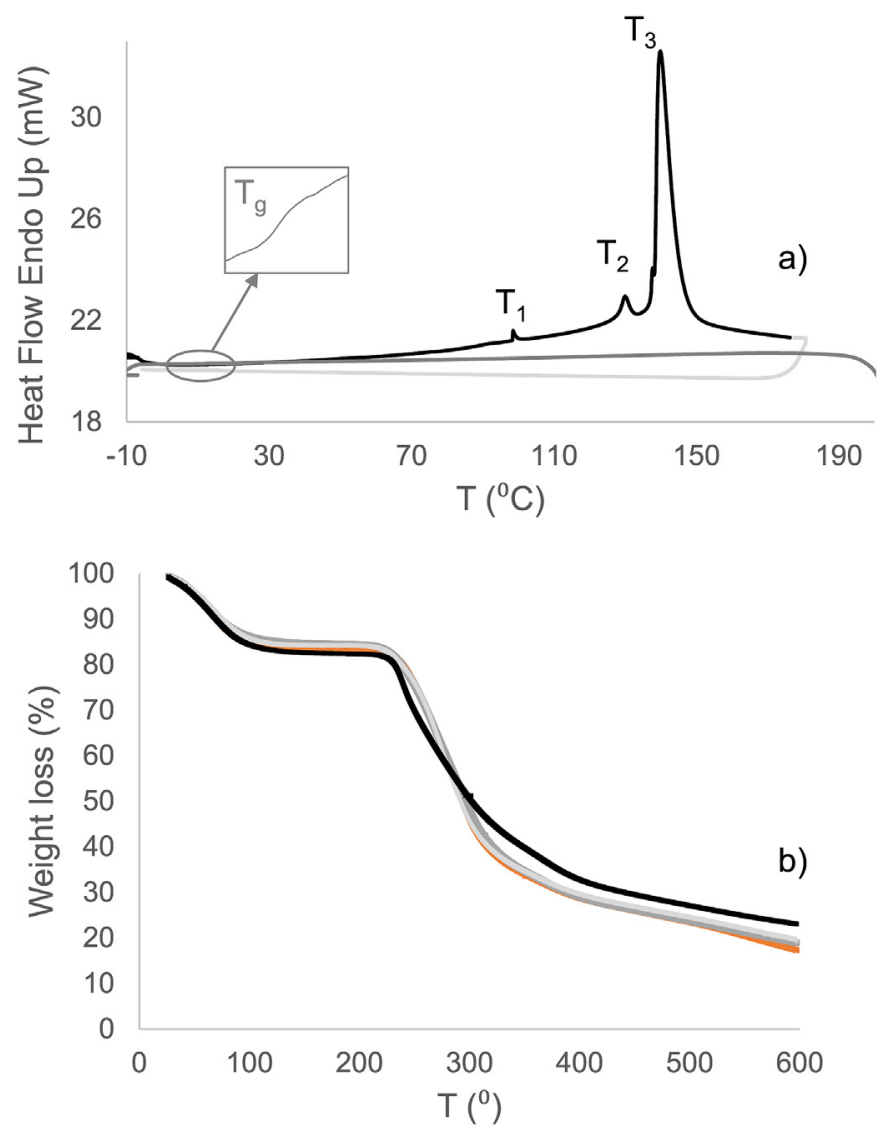

Fig. 7. Thermal behavior for the alkali-treated agar: a) Typical DSC thermogram (alkali-treated agar from Long Island Sound $1.0 \mathrm{~m}$ in 15/09): - First heating cycle; -- Cooling cycle; -- Second heating cycle; b) TGA: -- Long Island Sound 1.0 m 15/09; -- Long Island Sound 0.5 m 15/09; -- Long Island Sound 1.0 m 4/11; - Bronx River Estuary 1.0 m 2/11. 


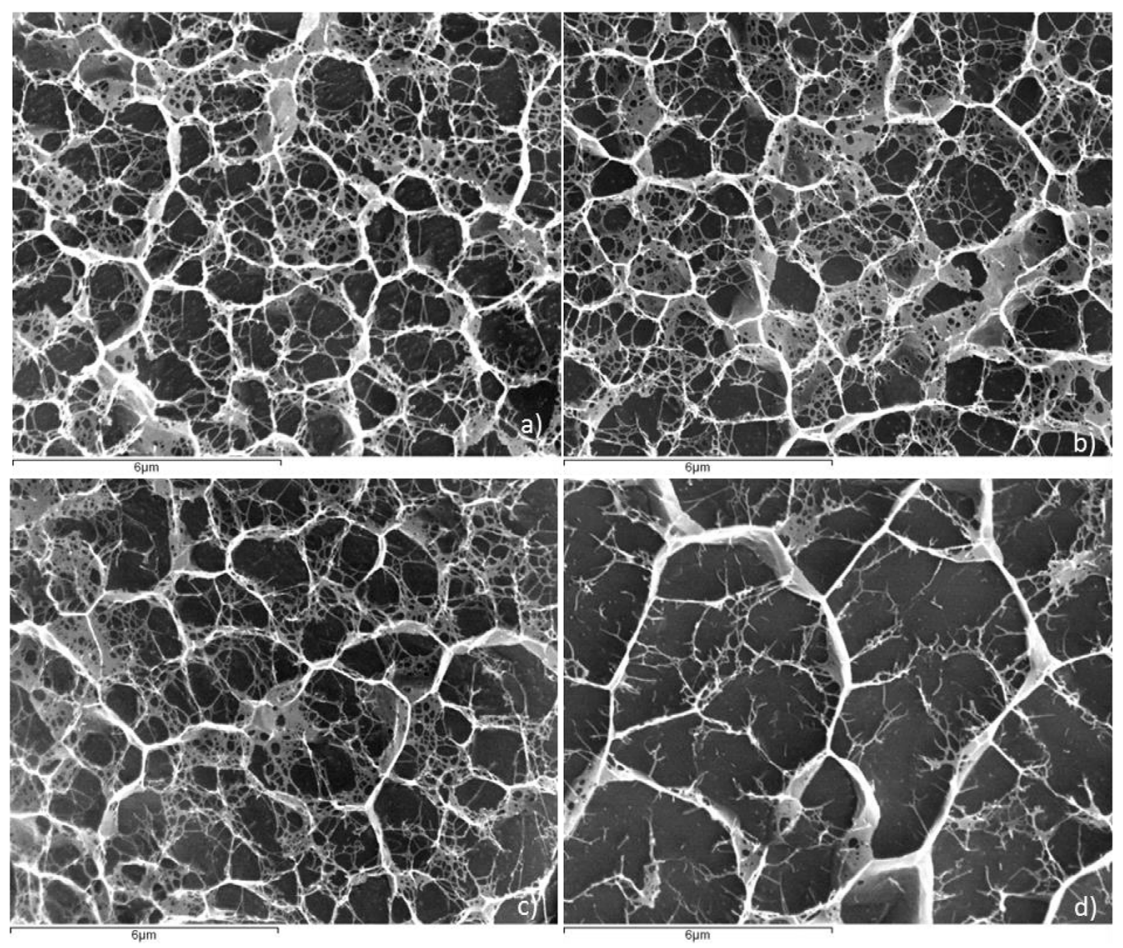

Fig. 8. CryoSEM pictures of agar gels: a) Long Island Sound $1.0 \mathrm{~m}$ 15/09; b) Long Island Sound 0.5 m 15/09; c) Long Island Sound 1.0 m 4/11; d) Bronx River Estuary $1.0 \mathrm{~m} \mathrm{2/11}$; error bar corresponds to $6 \mu \mathrm{m}$ in all pictures.

cultivation did not seem to have a significant effect, though the values for samples cultivated at $1 \mathrm{~m}$ were slightly higher, unlike the GS.

\subsection{DSC and TGA}

A typical thermogram achieved for DSC is presented in Fig. 7a. Three main endotermic peaks were detected in the first heating cycle: one slightly below $100{ }^{\circ} \mathrm{C}$, one around $130^{\circ} \mathrm{C}$ and the biggest one near $140^{\circ} \mathrm{C}$. The first peak is usually assigned to the residual water present in the sample (Ouyang et al., 2018). Peaks in the range of $126-144^{\circ} \mathrm{C}$ correspond to agar transitioning into the disordered state, from double helix to single chain. A corresponding transition was also seen in the rheological tests with high water content (gel melting $\mathrm{T}_{\mathrm{m}}$ ), but occurred at lower temperatures. This process was not reversible for low moisture samples (i.e. the sample does not resume its double helical state), but the second heating cycle showed a shift around $22.7^{\circ} \mathrm{C}$ (Table 4) for all analyzed agar samples, normally assigned to a glass transition. A commercial agar was used for comparison purposes and also showed a glass transition temperature at $23.4 \pm 0.4^{\circ} \mathrm{C}$. In fact, glass transition temperatures referred to in literature for low moisture agars but their final value is highly dependent on the type of agar, the moisture content and the drying history (Cooke, Gidley, \& Hedges, 1996; Mitsuiki, Yamamoto, Mizuno, \& Motoki, 1998).

Thermogravimetric analyses indicate two different regions of weight loss (Fig. 7b): a first one, up to $130{ }^{\circ} \mathrm{C}$, assigned to the removal of adsorbed and bond water and a second one starting from ca. $200{ }^{\circ} \mathrm{C}$, depending on the sample, assigned to thermal degradation. All samples presented similar weight loss patterns, though slight differences could be seen for the BRE sample in the thermal degradation region. In particular, the value of the temperature that corresponds to the minimum of the first derivative curve was significantly lower than the samples from the LIS site, corresponding to a maximum degradation rate at a lower temperature.

\subsection{Gelling and film forming ability}

\subsubsection{The gel structure}

As referred to in the introduction, the main food applications of agar are related with its gelling ability. Samples from late August and September presented quite high gel strengths matching the values of high quality commercial agars, confirming the commercial viability of the LIS agars. According to the criteria defined by the Japanese Specifications for Processed Agar (JSPA), all samples would be first grade food agar, with a GS higher than $350 \mathrm{~g} / \mathrm{cm}^{2}$ (Skriptsova \& Nabivailo, 2009). However, though late August to early October alkalitreated agars could be superior grade agars using these criteria (GS higher than $600 \mathrm{~g} / \mathrm{cm}^{2}$ ), their higher gelling temperatures hamper bacteriological and pharmaceutical applications.

Micrographs obtained from the cryo-SEM analyses of gels made from the extracted agar were in accordance with expectations resulting from the analyses of their chemical and physical properties (Fig. 8).

Data derived from agar gels of samples grown at different depths did not present any significant differences. The LIS gel from November presented a slightly more open network, which agreed with the slightly lower gelling strength, probably due to the residual presence of L6S groups. The BRE gels from November samples grown at $1.0 \mathrm{~m}$ produced the coarser network, due to the lowest gel strength, in spite of the high 3,6 AG value and low sulfate content. As the presence of L6S was similar to the LIS November sample, molecular weight was probably governing the gel structure. In fact, the molecular weight from the BRE sample was significantly lower than from the LIS sample (Table 4).

\subsubsection{Films}

Though the application as a food additive is the typical use in the food industry, much research work has been made assessing the viability of using agar-based materials for food packaging and edible coatings with interesting results. Therefore, agar samples collected at the LIS site from August till early October were mixed in a single batch and their edible-film forming ability was also tested. Mechanical properties, thickness, thermal properties (TGA) and water permeability 
of the films were assessed for benchmarking with agar-based films described in the literature.

Transparent and flexible films were obtained, with an average thickness of ca. $50 \mu \mathrm{m}$ (Table 5). Values found in literature for films produced by casting using formulations with agar and glycerol ranged from 37 to $60 \mu \mathrm{m}$ (Arham, Mulyati, Metusalach, \& Salengke, 2016; Kanmani \& Rhim, 2014; Malagurski et al., 2017; Phan, Debeaufort, Luu, \& Voilley, 2005; Shankar \& Rhim, 2016).

As for mechanical properties, the dispersion of values found in the literature is also high. Film forming solutions have agar concentrations ranging from 1 to $3 \%$ and glycerol (plasticizer) contents of $0-0.5 \mathrm{~g} / \mathrm{g}_{\mathrm{dry}}$ agar (Arham et al., 2016; Atef, Rezaei, \& Behrooz, 2014; Freile-Pelegrín et al., 2007; Kanmani \& Rhim, 2014; Malagurski et al., 2017; Mohajer, Rezaei, \& Hosseini, 2017; Phan et al., 2005; Rhim, 2011; Shankar \& Rhim, 2016; Sousa \& Goncalves, 2015; Wu, Geng, Chang, Yu, \& Ma, 2009). Though typical films conditioning for mechanical properties assessment is made at 50 or $53 \%$ relative humidity (RH), this is not frequently the case. As water has a strong plasticizer effect, mechanical properties will strongly differ upon RH variations. The achieved tensile strength (ca. $17 \mathrm{MPa}$ ) and elongation at break (ca. 11\%) are within the expected from the results reported with similar conditioning at $50-53 \%$ RH. Freile-Pelegrín et al. (2007) achieved a TS of 3.2 MPa and EB of $6.5 \%$ with $1.5 \%$ agar solutions without glycerol, but the agar used had a lower Mv (100 kDa) than the samples from LIS. Mohajer et al. (2017) reported a TS of $18.7 \mathrm{MPa}$ and an EB of $30 \%$, using $0.3 \mathrm{~g} / \mathrm{g}_{\text {dry agar }}$ of glycerol, Arham et al. (2016) reported a TS of $20 \mathrm{MPa}$ and a EB of $15 \%$ using $0.15 \mathrm{~g} / \mathrm{g}_{\text {dry agar }}$ of glycerol and Atef et al. (2014) reported a TS of $18 \mathrm{MPa}$ and a EB of 19 using $0.3 \mathrm{~g} / \mathrm{g}_{\text {dry agar }}$ of glycerol.

In terms of barrier to water, another important property for packaging and in particular, for food packaging, the dispersion in reported results is even higher. Phan et al. (2005), analyzed WVP conditioning samples at different $\mathrm{RH}$ and using different humidity gradients. For $3 \%$ agar solutions with $0.15 \mathrm{~g} / \mathrm{g}_{\text {dry }}$ agar of glycerol, they reported a WVP of $6 \times 10^{-11} \mathrm{~g} /(\mathrm{msPa})$, achieved conditioning films at $57 \%$ (slightly higher than the used in this work). Nevertheless, the results are in the same order of magnitude as this work, but slightly higher. Sousa \& Gonçalves (2015) also reported values of $4.6 \times 10^{-11}$ $\mathrm{g} /(\mathrm{msPa})$ for alkaline treated agars from Gracilaria vermicullophyla with no glycerol and Atef et al. (2014) reported $1.6 \times 10^{-10} \mathrm{~g} /(\mathrm{msPa})$ but using $0.33 \mathrm{~g} / \mathrm{g}_{\text {dry agar }}$ of glycerol and a commercial food grade agar. These are promising results, with water vapor permeability matching the values of cellophane as reported by Phan et al. (2005).

The properties of agar films are highly variable and strongly depend on several factors, including: the film forming methodology; plasticizer type and content; the presence of other additives; the source of agar and agar's properties; $\mathrm{RH}$ at which films are conditioning before analyses. Nevertheless, it can be concluded that films formulated with LIS agar samples matched the properties of other agar films and may be an interesting alternative application, both as edible films (as external packaging) or edible coatings (in direct contact with food). However, and as happens for other hydrocolloids, agar's price is still not competitive for packaging applications. Furthermore, biopolymers' performance continues to be a drawback for bioplastics applications. Therefore, most published articles involve strategies to improve mechanical and barrier properties including the inclusion of a reinforcing agent, such as nanoparticles, or the formulation in composites, taking advantage of synergies or interesting properties from other biopolymers (e.g. Malagurski et al., 2017; Shankar \& Rhim, 2016).

\section{Conclusions}

Previous studies showed that Gracilaria tikvahiae cultivated in open farms could be effectively used for nutrient bioextraction from urbanized estuarine waters, namely in Long Island Sound and the Bronx River Estuary, USA. Though Gracilaria/Gracilariopsis spp. are commonly used for agar production, information on agar from G. tikvahiae was scarce, probably because Gracilaria/Gracilariopsis have been mostly cultivated in China and Indonesia, and this particular species is not grown there. Furthermore, most reported yields for $G$. tikvahiae were low, not encouraging further industrial exploitation. Nevertheless, this study showed that it is possible to use G. tikvahiae biomass, cultivated in open waters, for agar production, which matches the performance of other Gracilaria agars used for food applications. Furthermore, this study also proved that an integrated strategy of nutrient bioextraction and agar exploitation is feasible, using the biomass from the first process as a sustainable source of seaweeds for the extraction of the hydrocolloid.

\section{Acknowledgments}

This work was supported by Fundação para a Ciência e a Tecnologia under the scope of the strategic funding of UID/QUI/50006/2013 and UID/BIO/04469/2013 units, COMPETE 2020 (POCI/01/0145/FEDER/ 007265 and POCI-01-0145-FEDER-006684) and BioTecNorte operation (NORTE-01-0145-FEDER-000004) funded by the European Regional Development Fund under the scope of Norte2020 - Programa Operacional Regional do Norte. The work was also supported by grants to C. Yarish and J. K. Kim from the U.S. EPA Long Island Sound Study's Long Island Sound Futures Fund, New York State Attorney General's Bronx River Watershed Initiative Grant Program, National Fish and Wildlife Foundation (NFWF/Legacy Grant Project IDs: 1401.10.024266 and 8012.08.030370), Connecticut Sea Grant College Program (R/A38) and the United States - Israel Binational Agricultural Research and Development Fund (BARD; US- 4599-13 R). Additional support was made by Basic Science Research Program through the National Research Foundation of Korea funded by the Ministry of Education (NRF-2017R1A6A1A06015181).

\section{References}

Abreu, M. H., Pereira, R., Yarish, C., Buschmann, A. H. \& Sousa-Pinto, I. (2011). IMTA with Gracilaria vermiculophylla: Productivity and nutrient removal performance of the seaweed in a land-based pilot scale system. Aquaculture, 312(1-4), 77-87.

Abreu, M. H., Varela, D. A., Henriquez, L., Villarroel, A., Yarish, C., Sousa-Pinto, I., et al (2009). Traditional vs. integrated multi-trophic aquaculture of Gracilaria chilensis C. J. Bird, J. McLachlan \& E. C. Oliveira: Productivity and physiological performance. Aquaculture, 293(3-4), 211-220.

Arham, R., Mulyati, M. T. Metusalach, M. \& Salengke, S. (2016). Physical and mechanical properties of agar based edible film with glycerol plasticizer. International Food Research Journal, 23(4), 1669-1675.

Arvizu-Higuera, D., Rodriguez-Montesinos, Y., Murillo-Alvarez, J., Munoz-Ochoa, M., \& Hernandez-Carmona, G. (2008). Effect of alkali treatment time and extraction time on agar from Gracilaria vermiculophylla. Journal of Applied Phycology, 20(5), 515-519.

Atef, M., Rezaei, M., \& Behrooz, R. (2014). Preparation and characterization agar-based nanocomposite film reinforced by nanocrystalline cellulose. International Journal of Biological Macromolecules, 70, 537-544.

Bird, N. L., Chen, L. C. M., \& McLachlan, J. (1979). Effects of temperature, light and salinity on growth in culture of Chondrus crispus, Furcellaria lumbricalis, Gracilaria tikvahiae (Gigartinales, Rhodophyta), and Fucus serratus (Fucales, Phaeophyta). Botanica marina: Vol. 22, (pp. 521-). .

Bird, K. T., Hanisak, M. D., \& Ryther, J. (1981). Chemical quality and production of agars extracted from Gracilaria tikvahiae grown in different nitrogen enrichment conditions. Botanica marina: Vol. 24, (pp. 441-). .

Bird, K. T., \& Hinson, T. K. (1992). Seasonal variations in agar yields and quality from North Carolina agarophytes. Botanica marina, Vol. 35, 291.

Bird, C. J., \& McLachlan, J. (1986). The effect of salinity on distribution of species of Gracilaria Grev. (Rhodophyta, Gigartinales): An experimental assessment. Botanica marina: Vol. 29, (pp. 231-).

Cheney, D. P., Mar, E., Saga, N., \& Meer, J. (1986). Protoplast isolation and cell division in the agar-producing seaweed Gracilaria (Rhodophyta). Journal of Phycology, 22(2), 238-243.

Cooke, D., Gidley, M. J., \& Hedges, N. D. (1996). Thermal properties of polysaccharides at low moisture. Journal of Thermal Analysis, 47(5), 1485-1498.

Costa, M. J., Marques, A. M., Pastrana, L. M., Teixeira, J. A., Sillankorva, S. M., \& Cerqueira, M. A. (2018). Physicochemical properties of alginate-based films: Effect of ionic crosslinking and mannuronic and guluronic acid ratio. Food Hydrocolloids, 81(8), 442-448.

Craigie, J. S., \& Jurgens, A. (1989). Structure of agars from Gracilaria tikvahiae, Rhodophyta: Location of 4-O-methyl-L-galactose and sulphate. Carbohydrate Polymers, 11(4), 265-278.

Craigie, J. S., \& Wen, Z. C. (1984). Effects of temperature and tissue age on gel strength 
and composition of agar from Gracilaria tikvahiae (Rhodophyceae). Canadian Journal of Botany, 62(8), 1665-1670.

Falshaw, R., Furneaux, R. H., \& Stevenson, D. E. (1998). Agars from nine species of red seaweed in the genus Curdiea (Gracilariaceae, Rhodophyta). Carbohydrate Research, 308(1-2), 107-115.

FAO (2016). The state of world fisheries and aquaculture 2016 - contributing to food security and nutrition for all. Rome.

Freile-Pelegrín, Y., Madera-Santana, T., Robledo, D., Veleva, L., Quintana, P., \& Azamar, J. A. (2007). Degradation of agar films in a humid tropical climate: Thermal, mechanical, morphological and structural changes. Polymer Degradation and Stability, 92(2), 244-252.

Ganesan, E. K. (1989). A catalog of benthic marine algae and seagrasses of Venezuela. Caracas: Fondo Editorial Conicit.

Givernaud, T., El Gourji, A., Mouradi-Givernaud, A., Lemoine, Y., \& Chiadmi, N. (1999). Seasonal variations of growth and agar composition of Gracilaria multipartita harvested along the Atlantic coast of Morocco. Hydrobiologia, 399, 167-172.

Gorman, L., Kraemer, G. P., Yarish, C., Boo, S. M., \& Kim, J. K. (2017). The effects of temperature on the growth rate and nitrogen content of invasive Gracilaria vermiculophylla and native Gracilaria tikvahiae from Long Island Sound, USA. ALGAE, 32(1), 57-66.

Jackson, S. G., \& McCandless, E. L. (1978). Simple, rapid, turbidometric determination of inorganic sulfate and/or protein. Analytical Biochemistry, 90(2), 802-808.

Kanmani, P., \& Rhim, J.-W. (2014). Antimicrobial and physical-mechanical properties of agar-based films incorporated with grapefruit seed extract. Carbohydrate Polymers, 102, 708-716.

Kim, J. K., Kraemer, G. P., \& Yarish, C. (2014). Field scale evaluation of seaweed aquaculture as a nutrient bioextraction strategy in Long Island Sound and the Bronx River Estuary. Aquaculture, 433, 148-156.

Kim, J. K., Kraemer, G. P., \& Yarish, C. (2015a). Use of sugar kelp aquaculture in long Island Sound and the Bronx River estuary for nutrient extraction. Marine Ecology Progress Series, 531, 155-166.

Kim, J. K., Mao, Y., Kraemer, G., \& Yarish, C. (2015b). Growth and pigment content of Gracilaria tikvahiae McLachlan under fluorescent and LED lighting. Aquaculture, 436, 52-57.

Kim, J. K., Yarish, C., Hwang, E. K., Park, M., \& Kim, Y. (2017). Seaweed aquaculture: Cultivation technologies, challenges and its ecosystem services. ALGAE, 32(1), 1-13.

Lahaye, M., \& Rochas, C. (1991). Chemical-structure and physicochemical properties of agar. Hydrobiologia, 221, 137-148.

Lapointe, B. E., Rice, D. L., \& Lawrence, J. M. (1984). Responses of photosynthesis, respiration, growth and cellular constituents to hypo-osmotic shock in the red alga Gracilaria tikvahiae. Comparative Biochemistry and Physiology Part A: Physiology, 77(1), 127-132.

Lewis, R. J., \& Hanisak, M. D. (1996). Effects of phosphate and nitrate supply on productivity, agar content and physical properties of agar of Gracilaria strain G-16S Journal of Applied Phycology, 8(1), 41-49.

Littler, D. S., \& Littler, M. M. (2000). Caribbean reef plants : An identification guide to the reef plants of the caribbean, Bahamas, Florida and gulf of Mexico. Washington, DC: OffShore Graphics, Inc.

Littler, D. S., Littler, M. M., Bucher, K. E., \& Norris, J. N. (1989). Marine plants of the caribbean: A field guide from Florida to Brazil. Washington, DC: Smithsonian Institution Press.

Lopezbautista, J., \& Kapraun, D. F. (1995). Agar analysis, nuclear genome quantification and characterization of 4 agarophytes (Gracilaria) from the Mexican Gulf-coast. Journal of Applied Phycology, 7(4), 351-357.

Malagurski, I., Levic, S., Nesic, A., Mitric, M., Pavlovic, V., \& Dimitrijevic-Brankovic, S. (2017). Mineralized agar-based nanocomposite films: Potential food packaging materials with antimicrobial properties. Carbohydrate Polymers, 175, 55-62.

Marinho-Soriano, E., \& Bourret, E. (2003). Effects of season on the yield and quality of agar from Gracilaria species (Gracilariaceae, Rhodophyta). Bioresource Technology, 90(3), 329-333.

Martin, L. A., Rodriguez, M. C., Matulewicz, M. C., Fissore, E. N., Gerschenson, L. N., \& Leonardi, P. I. (2013). Seasonal variation in agar composition and properties from Gracilaria gracilis (Gracilariales, Rhodophyta) of the Patagonian coast of Argentina. Phycological Research, 61(3), 163-171.

Mathieson, A. C., \& Hehre, E. J. (1986). A synopsis of New Hampshire seaweeds. Rhodora, 88(853), 1-139.

Matsuhashi, T. (1990). Agar. In P. Harris (Ed.). Food gels. Essex: Elsevier.

McHugh, D. J. (2003). A guide to the seaweed industry. Rome: FAO.

McLachlan, J. (1979). Gracilaria tikvahiae sp. nov. (Rhodophyta, Gigartinales, Gracilariaceae), from the northwestern atlantic. Phycologia, 18(1), 19-23.

McLachlan, J., \& Bird, C. J. (1984). Geographical and experimental assessment of the distribution ofGracilaria species (Rhodophyta: Gigartinales) in relation to temperature. Helgolaender Meeresuntersuchungen, 38(3), 319-334.

Mitsuiki, M., Yamamoto, Y., Mizuno, A., \& Motoki, M. (1998). Glass transition properties as a function of water content for various low-moisture galactans. Journal of Agricultural and Food Chemistry, 46(9), 3528-3534.

Mohajer, S., Rezaei, M., \& Hosseini, S. F. (2017). Physico-chemical and microstructural properties of fish gelatin/agar bio-based blend films. Carbohydrate Polymers, 157, 784-793.

Ouyang, Q. Q., Hu, Z., Li, S. D., Quan, W. Y., Wen, L. L., Yang, Z. M., et al. (2018). Thermal degradation of agar: Mechanism and toxicity of products. Food Chemistry, 264, 277-283.

Patwary, M. U., \& Meer, J. P. v. d. (1984). Growth experiments on autopolyploids of Gracilaria tikvahiae (Rhodophyceae). Phycologia, 23(1), 21-27.

Patwary, M. U., \& Vandermeer, J. P. (1983). Genetics of Gracilaria tikvahiae (Rhodophyceae). 9. Some propertiesof agars extracted from morphological mutants.
Botanica Marina, 26(6), 295-299.

Peckol, P., \& Rivers, J. S. (1995). Competitive interactions between the opportunistic macroalgae Cladophora vagabunda (Chlorophyta) and Gracilaria tikvahiae (Rhodophyta) under eutrophic conditions. Journal of Phycology, 31(2), 229-232.

Pereira, R., \& Yarish, C. (2008). Mass production of marine macroalgae. In S. E. Jørgensen, \& B. D. Fath (Eds.). Ecological engineering (vol. 3 of encyclopedia of ecology (pp. 2236-2247). Oxford: Elsevier.

Phan, T. D., Debeaufort, F., Luu, D., \& Voilley, A. (2005). Functional properties of edible agar-based and starch-based films for food quality preservation. Journal of Agricultural and Food Chemistry, 53(4), 973-981.

Porse, H., \& Rudolph, B. (2017). The seaweed hydrocolloid industry: 2016 updates, requirements, and outlook. Journal of Applied Phycology, 29(5), 2187-2200.

Rees, D. A. (1969). Structure, conformation, and mechanism in the formation of polysaccharide gels and networks. In R. S. T. Melville, L. Wolfrom, \& H. Derek (Vol. Eds.), Advances in carbohydrate chemistry and biochemistry: Vol. 24, (pp. 267-332). Academic Press.

Rhein-Knudsen, N., Ale, M. T., Ajalloueian, F., Yu, L. Y., \& Meyer, A. S. (2017). Rheological properties of agar and carrageenan from Ghanaian red seaweeds. Food Hydrocolloids, 63, 50-58.

Rhim, J.-W. (2011). Effect of clay contents on mechanical and water vapor barrier properties of agar-based nanocomposite films. Carbohydrate Polymers, 86(2), 691-699.

Rinaudo, M. (2008). Main properties and current applications of some polysaccharides as biomaterials. Polymer International, 57, 397-430.

Rochas, C., \& Lahaye, M. (1989). Average molecular weight and molecular weight distribution of agarose and agarose-type polysaccharides. Carbohydrate Polymers, 10(4), 289-298.

Rochas, C., Lahaye, M., \& Yaphe, W. (1986). Sulfate content of carrageenan and agar determined by infrared-spectroscopy. Botanica Marina, 29(4), 335-340.

Rodriguez, M. C., Matulewicz, M. C., Noseda, M. D., Ducatti, D. R. B., \& Leonardi, P. I. (2009). Agar from Gracilaria gracilis (Gracilariales, rhodophyta) of the patagonic coast of Argentina - content, structure and physical properties. Bioresource Technology, 100(3), 1435-1441.

Romero, J. B., Montano, M. N. E., Merca, F. E., Villanueva, R. D., Liao, M. L., \& Bacic, A. (2007). Seasonal variations in the composition and gel quality of agar from Gracilaria edulis in the Philippines. Botanica Marina, 50(3), 191-194.

Romero, J. B., Villanueva, R. D., \& Montano, M. N. E. (2008). Stability of agar in the seaweed Gracilaria eucheumatoides (Gracilariales, Rhodophyta) during postharvest storage. Bioresource Technology, 99(17), 8151-8155.

Rose, J. M., Bricker, S. B., Deonarine, S., Ferreira, J. G., Getchis, T., Grant, J., et al. (2015). Nutrient bioextraction. In R. A. Meyers (Ed.). Encyclopedia of sustainability science and technology (pp. 1-33). New York, NY: Springer New York.

Santos, R., \& Melo, R. A. (2018). Global shortage of technical agars: Back to basics (resource management). Journal of Applied Phycology, 30(4), 2463-2473.

Schneider, C. W., Suyemoto, M. M., \& Yarish, C. (1979). An annotated Checklist of Connecticut seaweeds: State geological and natural history survey of Connecticut. Department of Environmental Protection.

Selvalakshmi, S., Vijaya, N., Selvasekarapandian, S., \& Premalatha, M. (2017). Biopolymer agar-agar doped with NH4SCN as solid polymer electrolyte for electrochemical cell application. Journal of Applied Polymer Science, 134(15).

Shankar, S., \& Rhim, J.-W. (2016). Preparation of nanocellulose from micro-crystalline cellulose: The effect on the performance and properties of agar-based composite films. Carbohydrate Polymers, 135, 18-26.

Silva, K. S., Mauro, M. A., Goncalves, M. P., \& Rocha, C. M. R. (2016). Synergistic interactions of locust bean gum with whey proteins: Effect on physicochemical and microstructural properties of whey protein-based films. Food Hydrocolloids, 54, 179-188.

Skriptsova, A. V., \& Nabivailo, Y. V. (2009). Comparison of three gracilarioids: Growth rate, agar content and quality. Journal of Applied Phycology, 21(4), 443-450.

Sousa-Pinto, I., Murano, E., Coelho, S., Felga, A., \& Pereira, R. (1999). The effect of light on growth and agar content of Gelidium pulchellum (Gelidiaceae, Rhodophyta) in culture. Hydrobiologia, 399, 329-338.

Sousa, A. M., Alves, V. D., Morais, S., Delerue-Matos, C., \& Goncalves, M. P. (2010). Agar extraction from integrated multitrophic aquacultured Gracilaria vermiculophylla: Evaluation of a microwave-assisted process using response surface methodology. Bioresource Technology, 101(9), 3258-3267.

Sousa, A. M. M., Borges, J., Silva, F., Ramos, A. M., Cabrita, E. J., \& Goncalves, M. P. (2013). Shaping the molecular assemblies of native and alkali-modified agars in dilute and concentrated aqueous media via microwave-assisted extraction. Soft Matter, 9(11), 3131-3139.

Sousa, A. M., \& Goncalves, M. P. (2015). Strategies to improve the mechanical strength and water resistance of agar films for food packaging applications. Carbohydrate Polymers, 132, 196-204.

Sousa, A. M. M., Morais, S., Abreu, M. H., Pereira, R., Sousa-Pinto, I., Cabrita, E. J., et al. (2012). Structural, physical, and chemical modifications induced by microwave heating on native agar-like galactans. Journal of Agricultural and Food Chemistry, 60(19), 4977-4985.

Usov, A. I. (1984). NMR-spectroscopy of red seaweed polysaccharides - agars, carrageenans, and xylans. Botanica Marina, 27(5), 189-202.

Villanueva, R. D., Hilliou, L., \& Sousa-Pinto, I. (2009). Postharvest culture in the dark: An eco-friendly alternative to alkali treatment for enhancing the gel quality of kappa/ iota-hybrid carrageenan from Chondrus crispus (Gigartinales, Rhodophyta). Bioresource Technology, 100(9), 2633-2638.

Villanueva, R. D., Sousa, A. M. M., Goncalves, M. P., Nilsson, M., \& Hilliou, L. (2010). Production and properties of agar from the invasive marine alga, Gracilaria vermiculophylla (Gracilariales, Rhodophyta). Journal of Applied Phycology, 22(2), 211-220. 
Warren, F. J., Perston, B. B., Royall, P. G., Butterworth, P. J., \& Ellis, P. R. (2013). Infrared spectroscopy with heated attenuated total internal reflectance enabling precise measurement of thermally induced transitions in complex biological polymers. Analytical Chemistry, 85(8), 3999-4006.

Wu, Y., Geng, F., Chang, P. R., Yu, J., \& Ma, X. (2009). Effect of agar on the microstructure and performance of potato starch film. Carbohydrate Polymers, 76(2), 299-304.

Yaphe, W., \& Arsenault, G. P. (1965). Improved resorcinol reagent for the determination of fructose, and of 3,6-anhydrogalactose in polysaccharides. Analytical Biochemistry, 13(1), 143-148. 